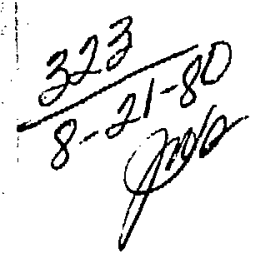

\title{
MASTER
}

D. 1663

\section{A hazard index for underground toxic material}

Craig F. Smith

Jerry J. Cohen

Thomas E. McKone*

$\omega$

June 1980

*University of Callfornia Los Angeles 


\title{
A hazard index for underground toxic material
}

\author{
Cralg F. Smith \\ Jerry J. Cohen \\ Thomas E. McKone*
}

Manuscript date: June 1980

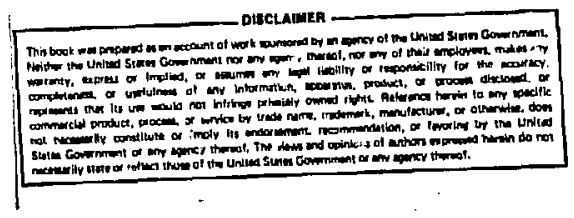

-Untrendty of Callforin los Angeles

\section{LAWRENCE LIVERMORE LABORATORY} University of California - Livermore, California • 94550

Available from: National Technieal Information Service - U.S. Department of Conmerse 5285 Port Royal Road a Springfield, VA 22161 - $\mathbf{7 . 0 0}$ per copy $\bullet$ (Microliche $\mathbf{3 3 . 5 0}$. 


\section{CONTENTS}

Abstract

$\mathrm{AB}-1$

Executive sumary $\ldots \ldots \ldots \ldots \ldots \ldots \ldots \ldots \ldots \ldots \ldots \ldots \ldots \ldots \ldots \ldots \ldots \ldots \ldots \ldots \ldots \ldots \ldots \ldots \ldots$

BS-1

1,0 Introductuon $\ldots \ldots \ldots \ldots \ldots \ldots \ldots \ldots \ldots \ldots \ldots \ldots \ldots \ldots \ldots \ldots \ldots \ldots \ldots \ldots \ldots \ldots \ldots \ldots \ldots$

1.1 Background and scope $\ldots \ldots \ldots \ldots \ldots \ldots \ldots \ldots \ldots \ldots \ldots \ldots \ldots \ldots \ldots \ldots \ldots \ldots$

1.2 The Uge of Indices for toxic Materials $\ldots \ldots \ldots \ldots \ldots \ldots \ldots \ldots \ldots \ldots$.

1.3 overviow $\ldots \ldots \ldots \ldots \ldots \ldots \ldots \ldots \ldots \ldots \ldots \ldots \ldots \ldots \ldots \ldots \ldots \ldots \ldots \ldots \ldots \ldots \ldots$

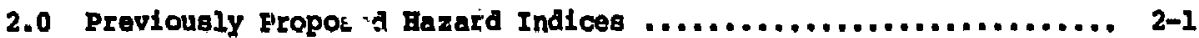

2.1 Introduction $\ldots \ldots \ldots \ldots \ldots \ldots \ldots \ldots \ldots \ldots \ldots \ldots \ldots \ldots \ldots \ldots \ldots \ldots \ldots \ldots \ldots . . \ldots 1$

2.2 General Qunlities of Environmental Indices and Measures .... 2-1

2.3 Discussion of Existing Indices $\ldots \ldots \ldots \ldots \ldots \ldots \ldots \ldots \ldots \ldots \ldots \ldots . . .2-2$

2.4 Characteristics Desired In a Geotoxiclty Hazard Index ...... 2-3

3.0 Development of a Hazard Index for Toxic Waste Buried in the

Earth's Crust $\ldots \ldots \ldots \ldots \ldots \ldots \ldots \ldots \ldots \ldots \ldots \ldots \ldots \ldots \ldots \ldots \ldots \ldots \ldots \ldots \ldots \ldots \ldots \ldots$ 3-1

3.1 Introduction $\ldots \ldots \ldots \ldots \ldots \ldots \ldots \ldots \ldots \ldots \ldots \ldots \ldots \ldots \ldots \ldots \ldots \ldots \ldots \ldots \ldots \ldots$

3.2 Development of a Measure of Hazard $\ldots \ldots \ldots \ldots \ldots \ldots \ldots \ldots \ldots \ldots \ldots . . . . . .1$

3.3 A Haztrd Measure for Stable Materials .................. 3-5

3.4 A Hazard Measure for Radloactive Materials .............. 3-6

3,5 The Generallzed Hazard Measure as the Basls of a Geotoxic Bazard Indlex ....................................... 3-7

3.6 A Proposed Geotoxic Hazard Index $\ldots \ldots \ldots \ldots \ldots \ldots \ldots \ldots \ldots \ldots \ldots \ldots . . . . \ldots$ 3-10

3.6.1 The Intrinsic Toxicity (TI) $\ldots \ldots \ldots \ldots \ldots \ldots \ldots \ldots \ldots \ldots$ 3-12

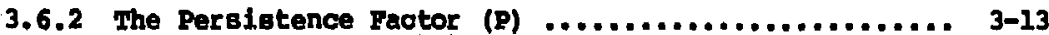

3.6.3 The Avallablitty Factor (A) .................. 3-15

3.6.4 The Bulldup Correction Factor (C) $\ldots \ldots \ldots \ldots \ldots \ldots \ldots . . . . .20$

3.7 Dlscussion $\ldots \ldots \ldots \ldots \ldots \ldots \ldots \ldots \ldots \ldots \ldots \ldots \ldots \ldots \ldots \ldots \ldots \ldots \ldots \ldots \ldots \ldots \ldots . . \ldots-22$ 
4.0 Semple Applications ............................. 4-1

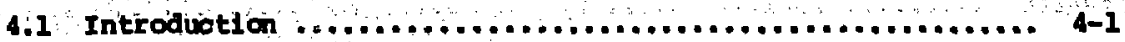

4.2 Descriptions of sample Inventorles, Assumptiong and

Bequl ts $\ldots \ldots \ldots \ldots \ldots \ldots \ldots \ldots \ldots \ldots \ldots \ldots \ldots \ldots \ldots \ldots \ldots \ldots \ldots \ldots \ldots \ldots \ldots \ldots, 4-1$

4.2 .1 A Iow-Level Waste traollity ................... 4-1

4.2.2 A Reference Algh-Level Waste Repositorg" .......... 4-3

4.2.3 A Reference Drantum ore Body .................. 4-5

4.2.4 Reference stable Metal Ore Bodles ................. 4-7

4.3 Discuselon $\ldots \ldots \ldots \ldots \ldots \ldots \ldots \ldots \ldots \ldots \ldots \ldots \ldots \ldots \ldots \ldots \ldots \ldots \ldots \ldots \ldots \ldots . . . \ldots 4$

5.0 gummary and conalustons $\ldots \ldots \ldots \ldots \ldots \ldots \ldots \ldots \ldots \ldots \ldots \ldots \ldots \ldots \ldots \ldots \ldots \ldots . . \ldots$

Appendix A. A Review of Indices Developed ts Heasure Environmental

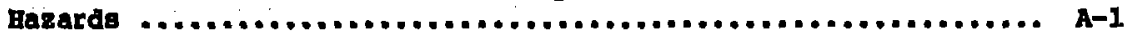

A.1 Introduction $\ldots \ldots \ldots \ldots \ldots \ldots \ldots \ldots \ldots \ldots \ldots \ldots \ldots \ldots \ldots \ldots \ldots \ldots \ldots \ldots \ldots$

A.2 General Qualitles of Environmental Indices and Measures .... A-2

A.3 Indices and Measures Devaloped for Ube with Radiotoxic vaceriale ..................................... A-3

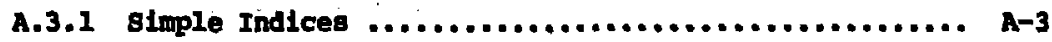

A.3.2 Fazard Indices Baged on Quantity and Toxicity ....... A-4

A.3.3 Radlotoxic Indicators Based on Qwantity, Toxic Character and Phyblcal Properties ................ A-14

A.3.4 Miscellaneout Indloes of Radiotoxlc Eazards ........ A-24

A.3.5 Risk Measures that Include Riok Perception ........ A-31

A.4 General Enviromental Indlces $\ldots \ldots \ldots \ldots \ldots \ldots \ldots \ldots \ldots \ldots \ldots \ldots \ldots$

A.5 Discuselon of Exlsting Indices ...................... A-45

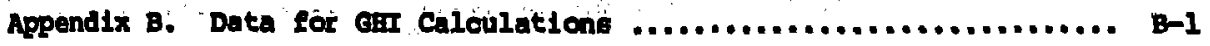

References $\ldots \ldots \ldots \ldots \ldots \ldots \ldots \ldots \ldots \ldots \ldots \ldots \ldots \ldots \ldots \ldots \ldots \ldots \ldots \ldots \ldots \ldots \ldots \ldots \ldots \ldots \ldots$ R-1 


\section{EXECUTIVE SUMMARY}

The emphasis in radioactive wate management has, historically, been concentrated on the methodological aspects of the problem-waste form development, alternative disposal technologiea, barrier design, etc.-while relatively little effort has been expended on charactorizing the basic nature of the problem. On the premise that an effective solution requires proper definition of the problem, this study secks to 1dentify guantitative measures to characterine the hazard of toxic materials incorporated in the earth'g crust.

The approach taken in this study was to review prevlous work in the development of toxic-material hazard measures and, from that review, to either select or develop a hazard index approprlate to toxic material in the earth's crust. scme desirable features of such an index are:

- The capability to assess the hazardous effects of both nonradicactive (chemical) and radoac sive toxic materials.

- The capability to assess natural minera! deposits and man-inade waste repositories containing radioactive or other toxic wastes.

- A simplicity of form, making it both understandable and applicable.

- A structure sufficient to characterize the parameters of primary Importance, Including toxiclty, persistence (longevity), and availabiliky (transport potential).

As a first step, we reviewed past efforts in the development of nonradiological and radiological hazard indices. After reviewing more than 40 references, we concluded that, although fectors currently used in 
toxicity measures apgear to have recelved bone degree of acceptance, other parameters of importance (persistence, avallability, and progeny. bulldug) have not been gatiafactor lly accomodated. Therefore, it was necessary to develop a new Index of hazard to provide these desired features.

In considering the apeotrum of posaible biological effects resulting from toxic material in the earth's cruat, we conoluded that the long-term chronic effecte reaulting from the ingebtion of material relased via water-borne pathweys was of overriding importance. In the present work, therefore, we consldered only the effeots due to chronic Ingestion. There potential acute effects, such as those resulting from direct Intruston Into and inhalation of the underground toxic matierial, are of concern, other hazard Indiceg would have to be developed to characterlze these problems.

A wathematicnl framework deflning a weasure of harard has been derived In this otudy. From this measure, a geotoxicity hazard index (GaI) is developed, it has the following form for any given element, radionuclide or material (1):

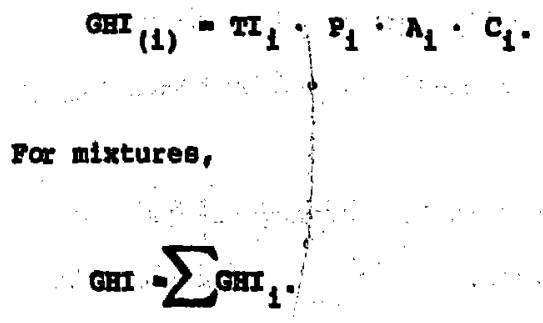


TI is a basic toxicity Index, and $P, A$, and $C$ are modifying factors related, respect vely, to perglotence, avallabllity and the kulidup of progeny more toxic than the parent material. speciflcally,

$$
\text { TI }=0 / \text { NOC or Q/DWS, }
$$

where

$$
Q \text { a the quantity of material (C1 or gm), }
$$

MPC = the max.tmum permisaible concentration for radionuclides in public drinking-water supplies $\left(\mathrm{Cl} / \mathrm{m}^{3}\right)$, and

DWs a the drinking-water standard or maximum permisgible concentration of atable toxic materials in public drinking-water supplies $\left(g \mathrm{~m} / \mathrm{m}^{3}\right)$.

Dimensionally, Tr 18 expressed in units of volube $\left(m^{3}\right)$. Conceptually, mi would indicate the volume of water required to dilute a given quantity of toxic material to drinking-water levels. Bowever, since TI does not convey all the Information desirable in characterizing the overall hazard, it is modified by the following dimensionless parameters:

- The peraistence factor (P) is calculated as

$$
P=\frac{I-\exp \left(-T^{\star} \cdot \operatorname{In}(2) / T_{1 / 2}\right)}{T^{\star} \cdot \lambda}
$$

where $\mathrm{T}_{1 / 2}$ is the half-ilfe in years, $\lambda$ is the corresponding decay constant, and $T^{*}$ is a reference time period, taken as 300 years in this work. For stable materialo, $P=1.0$ and for decaying material, $0<P<1.0$. - The availability factor (A) for material (1) Is related to the reference avallabllity $\left(A_{0}\right)$ of the same material (element) as it occurs naturally in the earth's crust, expressed as 


$$
A_{01}=\frac{\text { Ingestion rate (1)/arustal abundance }(1)}{\text { Ingest1on rate (Ra-226)/crustal abundance (Rs-226) }}
$$

In this formula, the natural avallability for any element 18 seen to be related to that of naturaily occurring Ra-226 so that, by definition, $A_{0}(R a-226)=1.0$. The actial avallability factor, $A_{1}$, 18 glven by $A_{1}=m \cdot A_{01}$, where in degcribes the modification of avallability for any given waste or mineral component, considering 1 ts chemical and physical form and conditions of burlal relative to that of its naturally occurring analog. Inoreasing degrees of isolation would result In lower values of $\mathrm{m}$. As a first approximation, it could be agsuned that $\mathrm{m}=1.0$. However, as new generle or site-specific information lo obtained through data acquisition, modeling, or other means, this value may be revised to Incorporate the new knowledge. $A_{0}$ is based on a gener lo understanding of the blogecohemlatry of an element. $A_{1}$ ls a refinement of $A_{0}$ based on a more detalled understanding of a particular toxic material deposit. Improvement in the estimation of $m$ (and therefore $A_{1}$ ) is been as an Iterative process in which newly obtained information will result in Increagingly accurate estimates of avaliablitity.

- The buildup correction factor (c) applies to materials that decay or transform Into progeny more toxic than the parent material, expressed as

$$
\text { c. } \frac{T H(\max )}{T_{0}}
$$

where $\mathrm{TI}_{(\max )}=$ the maximum total toxichty Index of the parent plus 
progeny mater lal at any future time and $\mathrm{Tr}_{0}$ the Initial toxiolty Index of the parent matertal.

We consldar ed some eample cases to demonstrate the application of the GaI A high-level waste repository, a low-level waste faclilty, and natural uranlum, lead, and meroury ore deposita were evaluated, The resul ts Indicated that the low-level waste faollity has a gonifleantly lower geotoxic hazard than that of the other iample cases considered. The curaory examples were assessed primar $11 y$ to demonstrate the methodology and to provide some insight into the relative importance of the Index componente. Further refinement of the calculational parameters, particularly the avaliability factor (A), will provide Increased confidence in the results. 


\subsection{INTKODUCTION}

\subsection{BACKGROIND AND SCOPE}

A notoworthy charaoterlotic of the radioaotlve waste management program has been the emphasis placed on methodology (waste form development, alternative dlaposal tochnologles, barrler deslgn, etc.) while relatively little effort has been expended on ratlonale for solution-that 18 , on characterizing the problem itself in guantitative terms.

To quantitatively define a problem, one must have a measuring tool, or yardstick. The yardstick must be deslgned to measure the area (s) of primary concern in problem definition (1,e., the hazara to the public, as opposed to the mase of toxic material, the number of curles of radlasctivity, or the number of lethal doses, etc.). It must also be applicable to the wide range of parametira that may be Involved in defining the problem.

This study seeks to ldentify an appropriate measure by reviewing past work and by selecting or developing en index of harard for application apeciflcally to toxic material incorporated in the earth's crust. The preponderance of methods applied or proposed for the ultimate disposal of radloactive or nonradioactive, hazardous waste Involve burial within tr arth. To develop a perspective on the rebujtant hazard, it 18, therefore, appropriate to determine a quantitative method by which to oharacterize the hazard of toxic material in the earth's cruat. To allow 
If or comparative evaluation, the method ohould be applleable to both rad odetive waste and nonfad loaotl vo toxla mater 1 ars. It ahould also be applicable whether the radoactive or toxlc materlal is Incorporated In the eartifo or ust by man or by nature.

Charactorization of the hazard due to toxid material within the Gartho oruat may be acoomplished with geotoxicity harard Index (GII). Geotoxlclty may bo defined as the harmeul effects resulting from toxic material buried in the earth's or ust, etther by men or by nature. The GEil muat be slimpla to use but camplex enough to permit the incorporation of factors deemed most Important in characterizing the overall hazard. It mugt alio be capable of handling a broad epectrum of toxic materlals to allow for incercompar 1son.

The GII is not Intended to replace the eystematic analyses required 3 the to determine the magnitude of opecific effects it can be useful, however, in placing the hazards in reasonable perspective to assist in the decteion-making process.

This gtudy reviews past work in the development of hazard indices, asseses previous approaches, and determines a hazard Index for toxlc mater lal in the earth's orust, satisfying the requirements discussed above.

\section{THE USE OF NDDICES FOA TOXIC MATERIALS}

A harerd Index for a toxic pollutant oan be defined as the measure of human exposure to that pollutant referenced to a corresponaing aocepted or geledted Ifmlt Chemlcals such as sulfur aloxide $\left(\mathrm{SO}_{2}\right)$, and oarbon monoxide $(\infty)$, which are continuously released into the atmogphere, raplaly reach local equllibrlum concentrations. Although 
exposure to these pollutents can be determined by measurenent or calculatfon the use of megures to chaseter ge hagard when , w stralghtforward environmental measurements do not apply 1 s nel ther olmple nor wldely acoomplighed.

What 18 an appropr iate messure for the hagard due to toxic mater Ial incorporated In the earth or ust? In contrast to atmospher 1o pollution exposure 18 now cestr lated by natural barrierg and cannot always be readily defined over the long time pertoda during which scme degree of 1solation is expected. There are many examples or this type of subsurface hazerd. Low-level radloactlve wastes are usually alsposed of by shallow land burial. Open-pit mining operations for copper, molybdenum, phosphates, and uranium produce tailing realdues that must be returned to the earth's crust. These residues are permeated with heavy metals and other toxic materials, including mercury, lead, cadmiun, zinc, arsentc, cyanlde, ammonia, ar radium. High-level radloactive wastes have been designated for disposal in geologic formations deep within the earth's crust. To be useful as a tool for assessing and comparing such waste-management problems, a hazard index should consider the significant factor affecting the hazard to man as a result of these operations, except for those low-probability hlgh-consequence events that can only be evaluated by rlak analysis.

\section{OVERVIEW}

Th1s etudy assesses previously developed hazard measures and developg a yeotoxicity hazard index that could be used In assessing 
the hazara of woste management, Thlo Index could be used to place problem in proper perspective or to set standards and criteria for the handilng and a ioposal of toxic mater lals. It cañ provlde direction for selecting optimal alternatives in waste management. A hazard Index Introdices a simple format for conveying Information on waste-disposal problems to both technical and nontechnical audiences. Pinally, it oan provide basis for comparing toxic materials (radloactive or ronradioactive) in tarms of the parameter of greatest concern, the potential hasard to the public. 


\subsection{PREVIOUSLY PROPOSED HAZARD INIICES}

\subsection{INTRODUCTION}

As part of this study, wo conduated a review of previously proposed hazard indices with the objective of either determining a satiofactory methodology in current existence or establishing the required character Iatics of a geotoxicity Index, sheuld one not be ayallable from previous efforts, Appendix A contains a detailed review of previous Indices developed to measure environmental harards. This section presente conclusions from the review.

From the review of past work, we determined the general qualitles of envirommental indices and measures and identified the required characteristics for a meaningful Index of geotoxic hazara.

This section summarizes the general qualities of environmental Indices and messures. Then it presents a discussion on previousiy proposed indices. Finally, it establishes the characteristics deemed most important for Incorporation Into the geotoxicity hazard index to be developed in the subsequent sections of this report. .:

\subsection{GENERAL QUALTIES OF ENVIRONMENTAL INDICES AND MEASURES}

The large number of enviramentel indices previously developed and utilized Indicates that no single Index has genera: applicability to the 
overaIl spectrum of problens. The review of previous indices revealed a wide variety of measires to characterize both radiotoxic hazards and general environmental quaity. A categorization of radiotoxic measures according to their structure is as follows:

(I) simple Indices based on quantity.

(2) Toxic Indices that account for both quantity and toxicity.

(3) Complex Indices that account for quantity, toxicity, and phyalcal properties.

(4) Complex indlces that consider quantity, toxicity, and physical properties and, is addition, incorporate parameters of value judgment.

For examples of Indices in each of these categor lea, refer to Appendix $A$.

\subsection{DISCUSSION OF EXISTING INDICES}

The distinction between toxicity and hazard is fundamental. For example, the lead in a standard automoblle battery is highly toxic. If relatively small quantities are ingested, this lead could be fatal. However, in 1 ts form and container, it is not generally considered hazardous because of the lack of a mechanlsm for exposure. The Iead in the exhaust from autcmoblies, on the other hand, may be both toxic and hazardous due to its direct avallabllity for human inhalation.

Many of the indices of hazard developed for radiotoxic materials are, In fact, basic toxlalty messures or varlations on these measures. These measures focus primar $11 y$ on the harm that will result from 
ingestion or inhalacion of a toxic material without considering the characterlatics and processes of the material, such as its chemical or physical form, dilution, and transport potential. The gimple toxicity Indices therefore consider the toxic effect, given that the matarial is assimilated in the body, but do not consider its potentlal for assimilation.

Those Indices that consider avallabllity often do so in ways that are complex and difficult to interpret or apply. Trestment of the character Istics and transport of toxic materials in a way wich is both meaningful and readily applicable would be a highly desirable extension of previous mork.

The time behavior of radioactive material has also been treated by Beveral authors. Their efforts have resulted. In a zomewhat arbitrary classiflcation system for persistence (Relquam, 1971) and in several attempts to quantitatively incorporate time factors (e.g., Gera and Jacobs, 1971). Unfortunately, treating stable materlals with these quantitative time iactors is difficult. Ideally, one would prefer a persiaterise factor that is quantitative, objective, and applicable to stable as we1l as to radioactive mater lals.

\subsection{CHARACTERISTICS DESIRED IN A GEOTOXICITY HAZARD INDEX}

In a general sense, an Index la a "comparison of a meagurable guantity to a standard" (Inhaber, 1976). In the specific realm of toxic mat ilal disposal, the hazard Index is a tool for condensing 
hazard-measure information, through some transformation, to provide quantitative results that are useful Indicators of the level of hazard or risk.

Several bastc parameters could be incorporated Into a meaningful hazard Index for toxic material burled underground. A list of potential paramaters is given in Table 2-1.

TABLE 2-1. Parameters that may be incorporated Into a geotoxicity hazard Index.

- Toxicity

- Persistence

- Avallability (transport potential)

- Decay product effects

- Chemical form

- Physical form

- Blanccumulation

- Percelved harm

of the above parameters, the rollowing are the minimum required to provide necessary detall to the hazard index:
(1) Intrinsic toxictty.
(2) Persiotence. 
(3) Availabilty (transport potential).

(4) Decay-product or transforıation effecte.

Factors such as chemical and physical form, depth, and location of the disposal repository or mineral body and bioaccumulation potential can be considered pertinent factors aflecting availability.

The Index should also be capable of handling both radioactive and nonradioactive materials. Although factors affecting perceived harm or risk are signiflcant (often of prliary importance in policy iaking), they are not consldered here. We believe that the most reasonable apgroach to the problem is to establish a propar technological perspective as a ftrst priority. Perceptual considerations should then be assessed within this technological framework.

From previous work, one can identify two approaches to index formulation. One approach is deterministic--employing mudels and experimental data to conatruct or Infer the functional dependence of hazari on the parameters involved. The simple toxicity index (TI) in which TI = Q/MPC (Btlliar, 1968) is a good example of this approach. Here $Q$ is the quantity of a toxic waterial, and IPC is the maximum permissible concentration, as desculbed in Appendix A.

A second approach could be described as a rating aystein. After Identifying "important" parameters (solubility, half-11fe, toxicity, blological retention, etc.), one assigns a numerical scoie to each parameter, using professional judgment, polling methods, or other nonrigorous methodology. In addition, an algortthm is developed to comblne the scores to define an owerall rating for each material. A 
somewhat more highly developed approach in this regard is the application of decision amalysis. The major drawback of such an index is that it is somewhat axbltrary since it depends largely on opinion or subjectively determined data. Such data can change drastically with time.

Our review of previous indices revealed that toxicity has been satisfactorily treated in a hazard index for radionuclides. The fact that the value Q/MPC or its equivalent has been extensively empluyed in the literature is indlcative of its role as an understandable and Informative index of toxicity. However, it is not c] ear that time behavior (pergigtence), avallability (related to waste form, disposal medium, and tranaport), or decay-product buildup have been incorporated with the same degree of success. For example, we have seen that the Initial approach to longevity proposed by Gera and Jacobs (1972) (1.e., multiplication of the hazard index by mean lifetime) results in an Infinite potential-hazard Index for atable toxic materiais. The "Transport Factor" Introduced by Bruns (1976! handles pathways to humans fer toxic material; but only as a consecutive linesr chain. In general, difficulty in the treatment of persistence and avallability comes as a result of introducing these characteristics in a manner that is either simple and arbitrary or that requires many complex calculations, thereby limiting utility. 'similarly, decay-chain effects have been largely Ignored.

It is possible that auccessful incorporation of persistence, avallabllity, and decay-chain effects Inte a hazard index could result from an approach analogous to the Q/MPC parameter for toxicity. The 
additional parameters needed to reflect time behavior, transport, and decay-iproduct buildup should be simple to employ and yet be based on observad data, expertmental data, generic transport modeling, or scme combiniation.

In the tradeoff between uimplicity and complexity, a simple, easy-ino-use index is consldered most desirable. The problem, then, is to incorporate enough complexity in the index to make 1 t meaningful but not Imposible or exceedingly difficult to implement.

Any effort to incorporate decision theory or risk perception into Indest development is excluded from this work. However, the present effort may provide a technological framework that could be incorporated ii future decision analyses.

To establieh an index applicable to toxic material in the earth's crust-a geotoxicfty hazard index-the following features are desired.

(1) The capa'ility to assess the hazardous effects of both nonradioactive and radioactive toxic material.

(2) The capability to assegs natural mineral deposits and man-made repositorles containing radioactive or other toxic wastes.

(3) A simplicity of form, making it understandable and readily applicable.

(4) A structure sufficient to characterize parameters of primary importance, Including toxicity, persiatence (longevity), a rallabllity (traneport potential), and trensformation-product effecta. The geotoxlcity hazard Index, which incorporates these desired features, will be presented and demonstrated in the following sections. 


\subsection{DEVELOPMENT OF A HAZARD INDEX FOR TOXIC WASTE BURIED IN THE EARTH'S CRUST}

\subsection{INTRODUCTION}

The objectives of this section are to extend the previoug work in order to determine a general measure of toxic material hazard and, from thls, to evolve an index characterizing the hazard of toxic material burled in the earth's crust.

It is important to distinguish between the terms "measure" and "Index" as used in this section. A measure is an exact quantification of some physical phenomenon (e.g., expected dose, toxicity, etc.), while an index is a less detafled quantification of relative values referenced to a standard and used for comparison. In general, an index should be derived from a measure using a transformation that may involve approximations and simplifications.

This section discusses the development of the Geotoxicity Bazard Index (GBI). First. the framework for a generalized hazard measure is derived. Then, a hazard index that meets the stated objectives (the GHI) is developed. The following section will include simple applications which demonstrate the use of the GHI.

\subsection{DEVELOPMENT OF A MEASURE OF HAZARD}

An ldeal geotoxic hazard measure indicates the exposure or harm at some definable time to humans (or some other blological entity) at a 
given geographic location as a result of the release of toxic material from the earth's crust. A formulation for such an ideal, gemeralized hazard measure will elrgt be derived. Approxinations in light of data base or mathematical ilmitations will be incerporated In the subsequent transition from a hazard measure to the geotoxiclty hazard Index.

A framework for conceptuallzing the dynamies of environnental transport results if one considers the earth as a aystem containing a large number of Interacting compartinentis. These compartments can be grouped into four major spheres: the biosphere, the atmosphere, the hydrosphere, and the 1ithosphere. Each of these spheres can be further diulded Into hundreds, thousands, and even millions of subcompartmeits depending on the complexity of the modeling approach and, more importantly, on the avallability of data. Each compartment interacts by some physical or chemical process with at least one other compartment so that no compartment is totaliy lsolated from the rest of the system. One of many possible modeis of the earth system 18 11lustrated in Fig. 3.1. Bach compartment 1llustrated here can be subdivided Into many subcompartmenta depending on one's perspective, sclentific discipline, and data. Any materlai placed in one compartment willi distribute Itself In some way among all of the envizonmental compartments one can define. ce course, the rate of distribution depends on the chemical form of the material, the environmental compartment in which it is first placed, and the transfer conslants between compartments. Trl.tium in the form of water placed in the Miesiasippl will distribute much more rapldly then lead placed in granite 600 meters below the earth's Burface. However, 
given enough time, the Iead may eventually appear in the Mississippi or oome other waterway.

The measure of hazard is defined by assuming that the earth can be divided into $\mathrm{N}$ compartments. Fusther, each material has a distribution function $f(1, j, k, t)$ that is defined as the fraction of material 1 . Initialiy placed in compartment $f$, which is destined to appear in compar tment $k$ at time $t$. Assuming this distribution function is $\mathrm{known}$ exactly (an assumption of infinite knowledge), two hazard measures can be defined: one for stable mater 1als and one for radioactive materials.

Note that the disinction between stable and radloactivem-may be somewhat arbltrary. 0amlum-186 has a half-11fe of $2.0 \times 10^{15}$ years-an instant in time when compared with the half-life of tellurium-128 at $1.5 \times 10^{24}$ years (Chart of the Nuclides, GE, 1977). In an ear1ier edition of the Chart of the Nuclides (GE, 1967), nelther of these nuclides was treated as radioactive. The point is that as more data beccme avallable, more nuclides are recognized as radioactive, and the distinotion between stable and radloactive becomes more academic." It is also of interest that the MPC for uranium-238 (ICRP, 1959) is based on Its chemical toxicity, rather than on 1ts radiotoxicity. Although this is an exception, it indicates that radiotoxicity does not always play the dominant role in defining the hazards of a mildly radioactive isotope.

\footnotetext{
"In discussing stabLlity and radioactivity as relative terms, it may be use ful to propose scme possible definitions by which to clasiffy materials: Any material that decays with a haif-iffe of less than $10^{6}$ years could be called radioactive. For half-11ves between $10^{6}$ and $10^{12}$ years, we would propose the term "radiopassive." For 18otopes with half-ifves in excess of 1012 years, we might apply the term "rodioquioscent," recngnizing that the truly stable materials form a subset of this classification, a subset which is apparently shrinking.
} 
For the purpase of this derivation, however, we initialiy will observe the traditionai cetegorization of nuclides into stable and radioactive materials and define two meseures of hamard. In the resulting Index of hazard, both stable and radioactive forms will be acconmodated by one formulat'.on.

\subsection{A HAZARD MEASURE FOR STABLE MATERIALS}

For a atable materlal, the toxic hazard measure is

$$
\operatorname{THM}_{1}(t)=Q_{1} \sum_{k} T_{1 k} f(1, j, k, t)
$$

where

$$
\begin{aligned}
& \operatorname{THM}_{1}(t)=\text { the instantaneous measure of toxic hazard to humans, } \\
& Q_{1}=\text { the Initial quantity of material } 1 \text { piaced in } \\
& \text { compartment } f(e . g, \text { grams), } \\
& T_{1 k}=\text { a meagure of toxicity per unit quantity, or specific } \\
& \text { toxicity of material } 1 \text { in compartment } k \text { (zero for } \\
& \text { many compar tments), and } \\
& E(1, j, k, t)=\text { distribution function (1,e., the fraction of } \\
& \text { material 1, Initially placed in compartment } J \text {, which } \\
& \text { Is deatined to appear in compartment } k \text { at time } t \text { ). }
\end{aligned}
$$




\subsection{A HAZARD MNASURE FOR RADIOACTIVE MATERIALS}

Because a radicactive 18otope decays along a chain of 1sotopes, its instantaneovis masasure of hazard is a more compllated function. Thus, for a radianctive nuclide 1 , which decays through a chain of isotopes Identified by $1(1=1,2,3 \ldots)$, the following form is appropriate

$$
\operatorname{IaM}_{1}(t)=Q_{1}(t) \sum_{k} T_{1 k} f(1, j, k, t)+\sum_{1 k} Q_{1}(t) T_{1 k} f(t-1, j, k ; t),
$$

where

$$
\begin{aligned}
& Q_{1}(t) \text { - time-dependent activity of nuclide } 1 \text { that results } \\
& \text { from an Initial quantity } Q_{0 i}, Q_{1}(t)=Q_{01} e^{-\lambda_{1} t} \text {, } \\
& T_{1 k}=\text { apecific toxicity (per unit activity) of nuclide } 1 \\
& \text { in compartment } k \text {, } \\
& f(1, j, k, t)=\text { dictribution function, } \\
& Q_{1}(t)=\text { time-dependent activity of isotope } 1 \text { that results } \\
& \text { from the radioactive transmutation of an Initial } \\
& \text { activity } q_{01} \text { of nuclide } i . Q_{1}(t) \text { can be } \\
& \text { obtained from } Q_{o 1} \text { through the equations of Bateman } \\
& \text { (1910). } \\
& T_{1 k} \text { specific toxicity of isotope } 1 \text { in compartment } k \text {. } \\
& f(t \rightarrow 1, f, k, t)=\text { distribution function for anit activity of isotope } \\
& 1 \text { which results from the transformation of materlal } \\
& 1 \text { through } 1 \text { to decay chain. }
\end{aligned}
$$

At present, we are only interested in the distribution of toxic material in one compartment-the compartment containing water and 
food Ingested by humans. The toxicity of nuclide 1 in this compartment is olmply designated $p_{i} ; a_{i}(t)$ is the fractional aviliability, and the distribution in this compartment is obtained from the following Bubstitutiong

$$
T_{1} a_{1}(t)=\sum_{j} f(1, j, k, t) T_{1 k}
$$

and

$$
T_{1} a_{l}(t)=\sum_{j} f(i \rightarrow 1, j, k, t) T_{1 k}
$$

From these simplifications, one obtains the following form for the hazard measure

$$
\operatorname{THM}_{1}(t)=Q_{o 1} e^{-\lambda_{1} t T_{1} a_{1}(t)+\sum_{1} Q_{1}(t) T_{1} a_{1}(t)}
$$

Although these hazard measures may be removed from practical application, they are important because they reflect the generalized framework that is intended and into which simplifications will later be introduced.

\subsection{THE GENERALIZED HAZARD MEASURE AS THE BASIS OF A GEOTOXIC HAZARD INDEX}

The index of hazard is a tool for condensing a large amount of Information (1.e., the hazard measure function) into a single value that helpg one understand the effect on the environment of scme perturbation in the toxic material content or distribution of the earth's crust. Our Interest is principally in an index of hazard for toxic materials buried 
either by man or nature in surface soils, at intermediate depths, or in deep geologic formations. To obtain this type of index, the generalized hazard measure is transformed through time integratica and gimplification.

Consideration of the problem at hand--providing a geotoxic hazard index-requires that we first develop an index that reflects local or regimal chronic doses from ingestion. This choice is made because the most likely dose pathways for crustolly deposited materlals aze low-level exposures via ingestion over prolonged time periods within a definite physical region. Phenomena such as erosion, volcanic eruption, human intrusion, and meteorite impact could release toxic material to the atmogphere, providing inhalation doses, however, they are not considered likely pathways and would have to be treated by probablilstic accident analysis. Our objective, therefore, is to determine a hazard index for the chronic effects of ingestion of either low-level radioactive or nonradioactive toxic material.

Por this purpose, conslder the previously defired radioactive material hazard measure for ingeation

where

$$
\operatorname{IHM}_{1}(t)=Q_{01} e^{-\lambda_{1} t} \mathrm{~T}_{1} a_{1}(t)+\sum_{1} Q_{1}(t) T_{1} a_{1}(t),
$$

$Q_{01}$ - initial inventory of material 1 that 18 buried $1 \mathrm{n}$ a defined region,

I - specific toxicity indlcative of the harmful effect per unit quantity of materlal 1 inge日ted,

$\lambda_{1}$ - decay constant,

$a_{1}(t)$ - Eraction of material 1 that is available for Ingestion by humans, 


$$
\begin{aligned}
Q_{1}(t)= & \text { quantity of naterial } 1 \text { resulting from the decay of } \\
& \text { an Initial quantity } Q_{\text {of }} \text { of material } 1 \text { into } 1 \text { ts } \\
& \text { daughters, } \\
T_{1}= & \text { specific toxicity of material } 1 \text {, and } \\
a_{1}(t)= & \text { Eraction of matex } 1 \text { al } 1 \text { that } 18 \text { avallable for } \\
& \text { Ingestion by humans. }
\end{aligned}
$$

The generalized hazard measure could also be written as

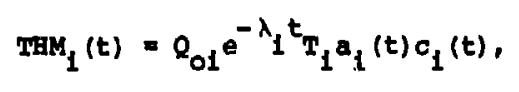

where

$$
c_{1}(t)=1+\frac{\sum_{1} Q_{1}(t) T_{1} a_{1}(t)}{Q_{01} e^{-\lambda_{1} t T_{i} a_{1}(t)}}
$$

Here $c(t)$ can be Interpreted as the factor by which toxicity changes as the parent decomposes and harmful daughter products accumulate. Note that for a stable material or one which has no significant toxic decay product, $c(t)=1.0$. Thus, we have incorporated the hazard measure for stable and radioactive materials Into a single unified form.

THI is expressed as a product of four basic terms: the time-dependent quantity of material and factors representing opecific toxiclty, avallablilty and decay-product bulldup.

Completion of the hazard index requires that we determine both a reference time period and a atandard of hazard or toxicity for comparison. First, ta'se the time perloo of $p$ gears as the reference 
period for fudging persistence. Next, assume that $T_{i}$ is a toxictty standard that expresses a level of drinking-water contandination to some reference concentration. S 15 a reference availability. Then, based on the previous discussion of the form of a hazard index, the geotoxic hazard Index ahould logically have the form

$$
\operatorname{GHI}_{1}=Q_{01} T_{1} \int_{0}^{* * \lambda_{1} t} a_{1}(t) c_{1}(t) d t / T^{*} s
$$

As a result of this opariation, the GII can be considered to be determined by four primary factors: total initial toxicity, time dependence (to be treated as "persistence"), availability, and decay-daughter effects.

\subsection{A PROPOSED 'GEOTOXIC HAZARD INDEX}

From the expreskions for ItEY and GaI In the prevtous section, we can expand and rearrange the terms so that

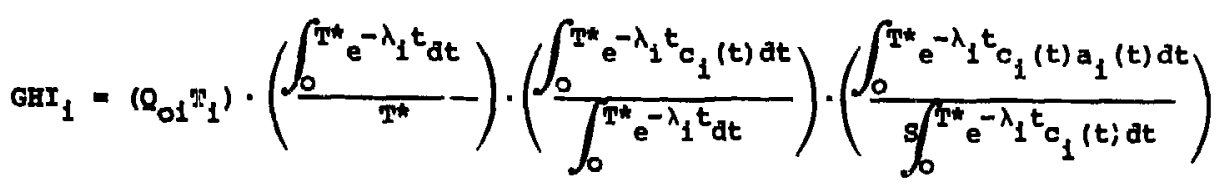

This rearrangement ailows us to extrac: terms in order to attach a better physical interpretation to the Index. We now define

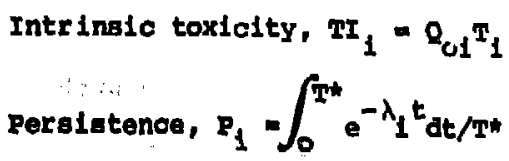

Decay-daughter correction factor, $c_{1} \frac{\int_{0}^{T^{*}} e^{-\lambda_{1} t} c_{1}(t) d t}{\int_{0}^{T^{*}} e^{-\lambda_{1} t} d t}$ 
Avallability index, $A_{1}=\frac{\int_{0}^{e^{*}} e^{-\lambda_{1} t} c_{1}(t) a_{1}(T) d t}{\int_{0}^{T *} e^{-\lambda_{1} t c_{1}(t) d t-s}}$.

Note that TI has the conventional meaning in terms of toxicity; persistence is a factor which ranges in value from 0 to 1 and Indicates the time persistence over the reference perlod $T^{\star}$, and $C_{1}$ and $A_{1}$ are time-averaged values which reflect decay daughter toxicity bulldup and avallability of the toxic material, relative to a standard. Thus, the Index consists of a ba ilc toxicity value that is modified by dimensionless parameters to accommodate other factors of concern: peralstence, avallability, and decay bulldup.

Using the foregoing definitions, the GaI can be expressed as

$$
\mathrm{GHI}_{1}=\mathrm{TI}_{1} \cdot \mathrm{P}_{1} \cdot \mathrm{C}_{1} \cdot \mathrm{A}_{1}
$$

For a mixture of materials,

$$
\mathrm{GHI}=\sum \mathrm{GBI}_{1} \text {. }
$$

As a result of the above expression for GHI, some physical inslght can be gained. The terms $\mathrm{TI}, \mathrm{P}, \mathrm{C}$, and $\mathrm{A}$ are indicators which, if known exactly according to their theoretical definitiona, would give a completely accurate representation of the hazard index. In practice, we can quantitatively evaluate TI and $P$ and determine conservative approximationa to $C$ and $A$ in order to make the Index easier to use without requiring complete knowledge about the behavior of the system. This approach can be implemented utilizing the current state of knowledge In terms of available data. As additional data become available, they 
can be easily incorporated to improve the calculation. In the following paragraphs, each term in thls formula is defined, and approximations and physleal interpretations are discussed.

\subsubsection{The Intringic Toxicity (MI)}

Intringle toxicity is the potential for harm that exists in a guantity of material initially placed underground;

$$
\text { MI }=Q_{1} T_{1}=Q_{1} / \text { WPC }_{1} \text { or } Q_{1} / D W S_{1} \text {, }
$$

where

$q_{1}$ - Initia. Inventory in grams, curies, etc., and

$T_{1}=$ specific toxicity consistent with the units in $Q$.

Because $\left(\right.$ MFC $^{-1}$ ) has gained wide acceptance on an indicator of speciflc toxicity, it is a logical cholce in applications to radiotoxic materials. For stable toxic materials, $T$ is taken as $\left(\mathrm{DWs}^{-1}\right)$, where DWB is a drinking-water atandard (mg/l) corresponding to the maximum permisaible concentration for toxic (including radiotoxic) material in public water supplies. Implied is the assumption that DWS is analogous to the MPC in that exposure to efther corresponda to an equili ilent level of hazard. The valldity of this assumption was studied previourly by Tonnessen and Cohen (1977). That study concluded that the two sets of stanoisds, although not rigorously ldentical, can be compared because both were formulated from the same premises, that 18, both standards may be consldered maximim acceptable levels for the continuous public consumption of drinking water without undue hazard. In addition, 
both approaches are consistent in that they result in units of volume. Also note that neither value is considered a perfect determinant of toxic hazard. For example, the effecta of exposure to levels above MPC or Drs would mogt likely not scale similarly for all materials. In the present context (law-level chronic exposure), however, the differences in scaling effects below the guideline values are not considered oufficient to Invalidate their use as Indices of toxioity.

In Appendix A of this study, we note that many agencles have specifled MPCs and that there are varlations anong them. We sha11 use the values presented In IAßA-9 (1962) since, the IARA values for radionuclides are fudged to be reasonably conslstent with current drinking-water standards for stable materials.

\subsubsection{The Persibtence Factor (P)}

The persistence factor can be Interpreted as an adjustment to Intringle toxiclty, which accounts for the diminished damage potential of materlals that are self-reducing through radloactive decay or some other transfcrmation process. For a atable material, $P$ is assigned a value of 1.0, Indicative of the maximum persiatence possible (1.e.., an infinite half-ilfe). For materlals that diminish with time, $P$ has a value between

0 and 1 depending on the half-life of the process. P Is defined mathematically as

$$
P=\frac{1-\exp (-T * \cdot \ln (2) / T 1 / 2)}{T \cdot \lambda}
$$


where $T_{1 / 2}$ is the half-life in years, $\lambda$ is the corresponding decay constant, and $T^{*}$ is the time interval against which persistence is judged. Phyaically, $p$ corresponds to the average fraction of materlal $i$ available in the time period $T^{*}$, as can be seen in FIg. 3.2 .

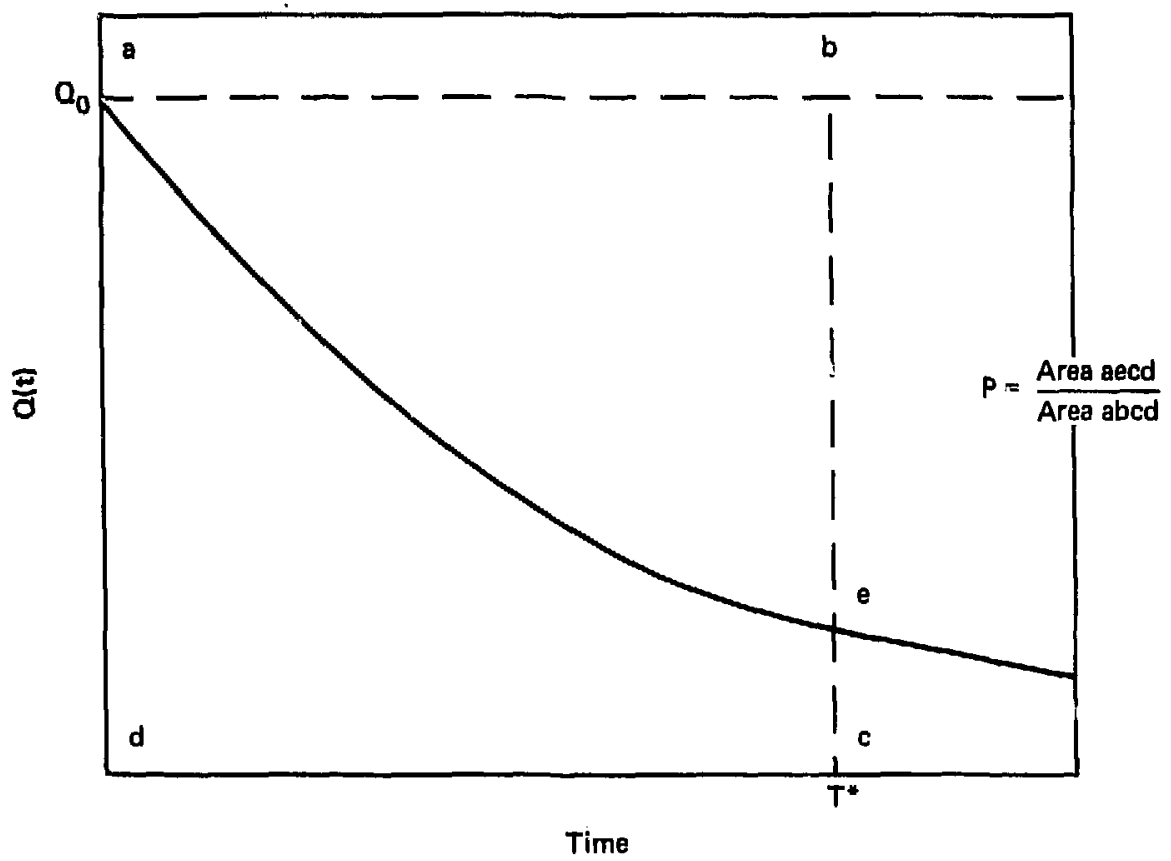

Figure 3.2 Geometric interpretation of persistence

For the purpases of this work, mt is given the value of 300 years. This tine porlod io based on the following conglderationst

- In condidering the distribution of half-lives for redloactive meerlale, 300 years da a logical break polnt. Very fen radionuclide 
half-lives fall in the range of 100 to 1000 years. Of the more than 1000 nuclides 11 sted in the Chart of the Nuclldes (GB, 1977), Only gix have half-lives in this range. Three-hundred years is approximately the gecmetric average of these limits.

- Th1s time frame is reasonably representative of the stability of such social Ingtitutions as government. It 1s, therefore, a period during which it is reasonable to assume that administrative control may be maintained over a hazardous waste repository.

- It can be considered a reasonable limit of prediction for trangport processes.

- It corresponds to a time period that defines 10 half-lives of Sr-90 and $\mathrm{CB}-137$, two of the most important constituents of radioactive waste. In 10 half 11 ves, the quantities of these materials are reduced by three orders of magnitude, a widely used cule of thumb for specifylng decay to innocuous levels.

Although the cholce of 300 years may not be numerically rigorous, it offers an appropriate time interval over which to judge persistence. The varlation of persistence with choice of $T^{\text {th }}$ ls demonstrated in F1g. 3.3.

\subsubsection{The Avallablilty factor (A)}

A 18 the average toxic avallabllity divided by a standard $\mathrm{s}$. In terms of the original mathematical definition

$$
A_{1}=\frac{\int_{0}^{2 *} e^{-\lambda_{1} t c_{1}(t) d_{1}(t) d t}}{\int_{0}^{-\lambda_{1} t c_{1}(t) d t \cdot s}}
$$




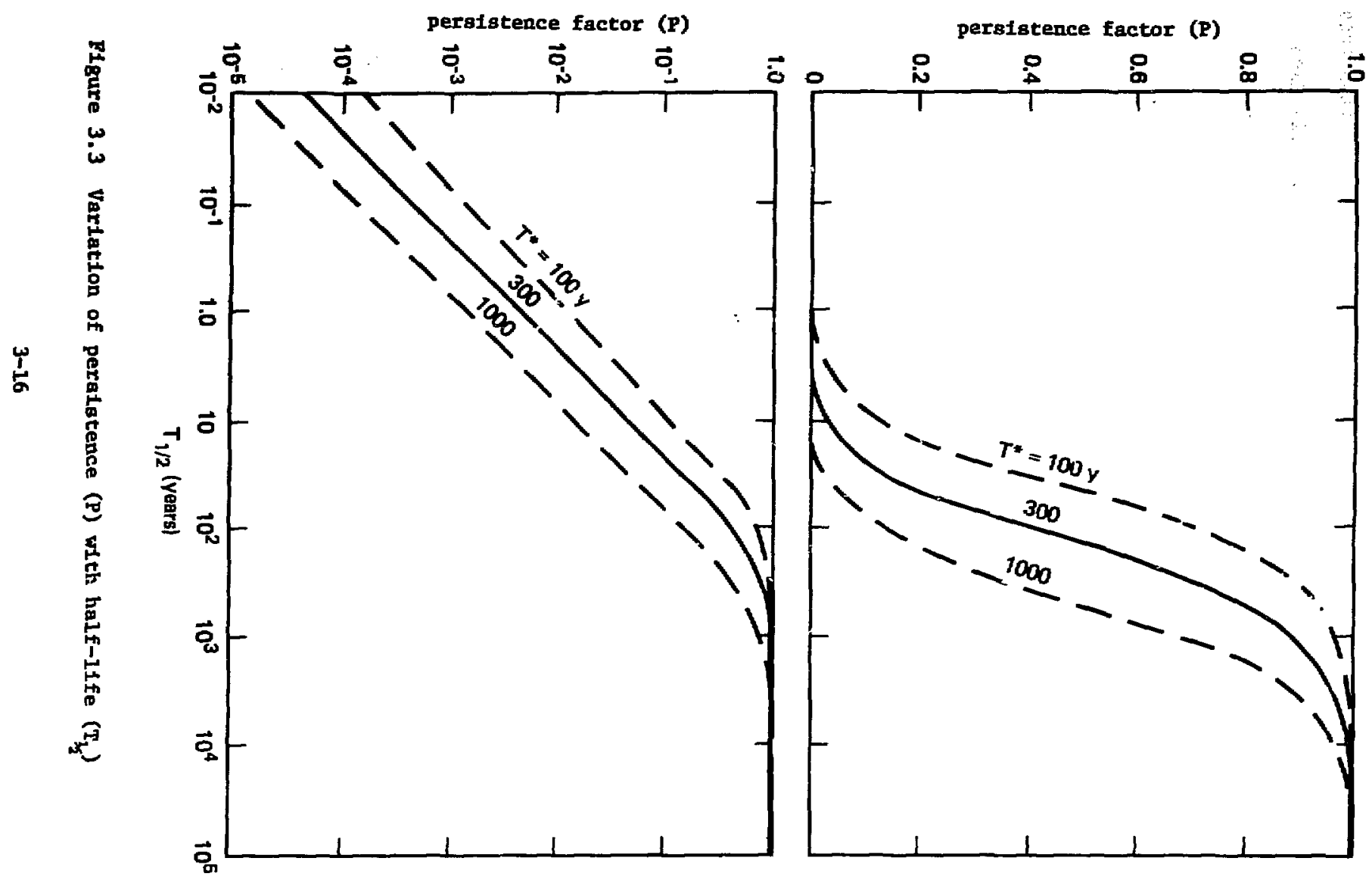


A can be viewed as the "effective" availability of toxic material, including parent and decay products, over the time period $w^{*}$. In implementing the hazard index, however, A will be conservatively assigned a peak or long-term value that may or may not occur within the time frame represented by $T^{*}$. The following paragraphs diacuss the conceptual definition and method for determining $A$ as used in this study. The existence of toxic material within the earth's crust would constitute no hazard were it not for 1 ts potential for release, transport to, and agsimilation in human tigsue. The avallability of the material 18, therefore, an 1mportant parameter in the determination of hazard. The transport of toxlo materials from the eart:'s crust involves complicated migration paths-into groundwaters, surface waters, solls, sediments, etc. From these compartments, there are pathways through drinking water and food to man. Trying to incorporate all that is known about these pathways (and, more importantly, all that is not known) Into the term $A$ would be a monumental and untenable task. It is possible, however, to make a reasonable approximation of the overall phenomenology, using the approach suggested by Cohen and Jow (1978). Th1s approach Is based on the observation that all mineral elementa Ingested by humans have their origin in the earth's crust and that, for each chemical element, there is a balance between the crustal abundance, the Ingestion rate, and the tlssue content. When this balance 18 altered, disease often resulta. Manifestations of these phenomena are observed in toxic conditions such as pluorosis (flu rine) and Ital-Ital disease (cadmium). The opposite is also observed in deflciency alseases such as golter 
(lodtne) and Imreased dental aries (fluorine). Dletary aupplemencs of minerala are often taken to avold auch conditions.

The normal average avallability $\left(\mathrm{A}_{0}\right)$ of elenente from the earth's cruat can be repreaented by decermining the ratio of intake to crustal abundance and by comparing this ratio to some standard. For this purpose, we can use naturally occurring radium-226. The "background" or normal avallability Eactor $\left(A_{0}\right)$ fin naturally ocourring elements is deterintined by

$$
A_{01}=\frac{\text { Ingestion cate (1), crustal abundance }(1)}{\text { Ingestion rate }(R a-226) / \text { cruatal abundance }(R a-226)}
$$

Data for decermining $A_{0}$ are taken from Cohen and Jos (1978) and presented In Table 3-1. For elements not listed (e.g. man-made elements), the procedures given by Cohen and Jow are used. These data are representative of the average distribution of elements in the top 12 m of soll in the United states. All other factors being equal, it is reasonable to asaume that any radionuclide will behave as 1 ts atablr element analog. In speciflo geographic or operational cases, the avallablilty would probably deviate (Increase or decrease) from the referonce velue $\left(A_{0}\right)$. For exauple, si a noar-surface waste repository the actual avaliablitty of the waste materlal might be increaged. gimilarly in a deep repository contalning waste in a stablilged form, the avallability would moet 11kely decrease greatly. Any Identified modifloation from natural or bnokground avallabllity may be incorporated 
TABLE 3-1. Data for determination of $A_{0}$.

\begin{tabular}{|c|c|c|c|c|c|c|c|c|c|}
\hline Element & $\mathbf{z}$ & $\begin{array}{l}\text { Intake } \\
\text { (g/day) }\end{array}$ & $\begin{array}{l}\text { Abundance } \\
\text { in sediment } \\
\text { (ppm) }\end{array}$ & $\begin{array}{c}\text { Intake/ } \\
\text { abundance } \\
\text { (g/day)/ppm }\end{array}$ & Element & $\mathbf{z}$ & $\begin{array}{l}\text { Intake } \\
\text { (g/day! }\end{array}$ & $\begin{array}{l}\text { Abundance } \\
\text { in sediment } \\
\text { (ppi) }\end{array}$ & $\begin{array}{c}\text { Intake/ } \\
\text { abundaruce } \\
\text { (g/day)/pgm }\end{array}$ \\
\hline $\mathbf{L i}$ & 3 & $2.0 \times 10^{-3}$ & 38 & $5.2 \times 10^{-5}$ & $\mathbf{z n}$ & 30 & $13 \times 10^{-3}$ & 52 & $2.5 \times 10^{-4}$ \\
\hline $\mathrm{Be}$ & 4 & $12 \times 10^{-6}$ & 1.9 & $6.3 \times 10^{-6}$ & Ge & 32 & $1.5 \times 10^{-3}$ & 1.4 & $1.1 \times 10^{-3}$ \\
\hline B & 5 & $1.3 \times 10^{-3}$ & 68 & $1.9 \times 10^{-5}$ & As & 33 & $1 \times 10^{-3}$ & 1.8 & $2.4 \times 10^{-4}$ \\
\hline$c$ & 6 & 300 & & 1.5 & Se & 34 & $1.5 \times 10^{-4}$ & 0.36 & $4.2 \times 10^{-4}$ \\
\hline $\mathbf{N}$ & 7 & 16 & 600 & $2.7 \times 10^{-2}$ & $\mathrm{Br}$ & 35 & $7.5 \times 10^{-3}$ & 4.8 & $1.6 \times 10^{-3}$ \\
\hline 0 & 8 & 2600 & 4560 & $5.8 \times 10^{-1}$ & $\mathbf{R h}$ & 37 & $2.2 \times 10^{-3}$ & 127 & $1.7 \times 10^{-5}$ \\
\hline $\mathbf{F}$ & 9 & $1.8 \times 10^{-3}$ & 410 & $4.45 \times 10^{-6}$ & $\mathbf{s r}$ & 38 & $1.9 \times 10^{-3}$ & 375 & $5.1 \times 10^{-6}$ \\
\hline $\mathrm{Na}$ & 11 & 4.4 & 4560 & $1.0 \times 10^{-3}$ & $\mathbf{z r}$ & 40 & $4.2 \times 10^{-3}$ & 165 & $2.5 \times 10^{-5}$ \\
\hline Mg & 12 & 0.3 & 18100 & $1.7 \times 10^{-5}$ & Nb & 41 & $6.2 \times 10^{-4}$ & 11 & $5.6 \times 10^{-5}$ \\
\hline AI & 13 & $45 \times 10^{-3}$ & 65300 & $7.0 \times 10^{-7}$ & Mo & 42 & $3 \times 10^{-4}$ & 1.2 & $2.5 \times 10^{-4}$ \\
\hline $\mathbf{s i}$ & 14 & $3.5 \times 10^{-3}$ & 226200 & $1.6 \times 10^{-8}$ & Ag & 47 & $7 \times 10^{-5}$ & 0.08 & $8.8 \times 10^{-4}$ \\
\hline $\mathbf{P}$ & 15 & 1.4 & 550 & $2.5 \times 10^{-3}$ & ca & 48 & $1.5 \times 10^{-4}$ & 0.19 & $7.9 \times 10^{-4}$ \\
\hline $\mathbf{S}$ & 16 & 0.85 & 1970 & $4.3 \times 10^{-4}$ & Sn & 50 & $\times 10^{-3}$ & 5.8 & $6.9 \times .10^{-4}$ \\
\hline $\mathbf{C l}$ & 17 & 5.2 & 130 & $4.3 \times 10^{-2}$ & $\mathbf{s b}$ & 51 & $\times 10^{-5}$ & 1.2 & $4.2 \times 10^{-5}$ \\
\hline $\mathbf{K}$ & 19 & 3.3 & 15850 & $2.1 \times 10^{-4}$ & $I$ & 53 & $\times 10^{-4}$ & 1.2 & $1.7 \times 10^{-4}$ \\
\hline $\mathrm{Ca}$ & 20 & 1.1 & 81000 & $1.4 \times 10^{-5}$ & Cs & 55 & $1 \times 10^{-5}$ & 7 & $1.4 \times 10^{-6}$ \\
\hline Ti & 22 & $0.85 \times 10^{-3}$ & 2360 & $2.9 \times 10^{-7}$ & $\mathbf{B a}$ & 56 & $0.75 \times 10^{-3}$ & 460 & $1.6 \times 10^{-6}$ \\
\hline $\mathbf{v}$ & 23 & $2 \times 10^{-3}$ & 81 & $2.5 \times 10^{-5}$ & Tl & 81 & $1.5 \times 10^{-6}$ & 0.77 & $1.9 \times 10^{-6}$ \\
\hline Cr & 24 & $1.5 \times 10^{-4}$ & 67 & $2.2 \times 10^{-6}$ & $\mathbf{P b}$ & 82 & $0.44 \times 10^{-3}$ & 14.6 & $3.0 \times 10^{-5}$ \\
\hline Mn & 25 & $3.7 \times 10^{-3}$ & 596 & $6.2 \times 10^{-6}$ & $B i$ & 83 & $20 \times 10^{-6}$ & $0.01-10$ & $2.0 \times 10^{-3}$ \\
\hline $\mathrm{Fe}$ & 26 & $14 \times 10^{-3}$ & 21700 & $6.5 \times 10^{-7}$ & $210_{\mathrm{PO}}$ & 84 & $7.13 \times 10^{-16}$ & $1.67 \times 10^{-10}$ & $4.3 \times 10^{-6}$ \\
\hline Co & 27 & $3 \times 10^{-4}$ & II & $2.7 \times 10^{-5}$ & $226_{\mathrm{Ra}}$ & 88 & $2.35 \times 10^{-12}$ & $7.59 \times 10^{-7}$ & $3.1 \times 10^{-6}$ \\
\hline $\mathbf{N i}$ & 28 & $4 \times 10^{-4}$ & 58 & $6.9 \times 10^{-6}$ & Th & 90 & $3 \times 10^{-6}$ & 6.9 & $4.3 \times 10^{-7}$ \\
\hline $\mathrm{Cu}$ & 29 & $3.5 \times 10^{-3}$ & 34 & $1.0 \times 10^{-4}$ & ס & 92 & $1.9 \times 10^{-6}$ & 2.3 & $8.3 \times 10^{-7}$ \\
\hline
\end{tabular}

Data taken from Cohen and Jow (1978). 
In a modification term (m) defined as

$$
m=\frac{A_{1}}{A_{01}}
$$

where $A_{1}$ is the actual avallability of a given material (element) in its apecific chemical and physical form and particular geologic setting. Determination of the value of the modification term $\mathrm{m}$ is considered an iterative process, whtre the improved information can be incorporated to yield more accurate estimates as new data or Insights are obtained. Where apecific information on availabllity is lacking, a reasonable firat approximation of $\mathrm{m}$ would be unity for each elemental component in a waste repository or mineral deposit (i,e. $A_{1}=A_{01}$ ). As new information accumulates, improved estimates of m may be derived by either calculational or empirical methods. This area should be a focal point for tmprovement based upon environmental measurements, experimental data, or large-scale-transport modeling efforts. Factors affecting $\mathrm{m}$, such as depth of burial, waste form, and geological and hydrological conditions, are being studied extensively. Application of the GHI approach can provide a framework for placing the results of studies in reasonable perspective.

\subsubsection{The Buildup Correction Factor (C)}

C is the buildup correction factor and is expressed mathematically as

$$
c_{1}=\frac{\int^{T_{*}^{*}} e^{-\lambda_{1} t} c_{1}(t) d t}{\int_{0}^{T^{*}} e^{-\lambda_{1} t} d t}
$$


where $c_{i}(t)$, as previously defined, is a factor that reflects the buildup of harmful decay products. As for the availability factor, $c$ will be conservatively evaluated according to actual decay toxicity buildup, withcut requiring that the effects take place within the time frame denoted by $T^{*}$. The following paragraphs will discuss $c$ as defined concoptually and as used in this study.

The correction factor (C) provides for the modification of the GHI to account for materials that decay or transform into progeny more hazardous than the parent material. In the vast majority of cases, the parent material is more hazardous than 1 ts decay or transformation products, and correction is unnecessary (1.e., $c=1.0)$. A notable exception is uranium-238, whose decay chain includes radium-226 and ends with stable lead-206. The latter nuclides are significantly more toxic than the'parent material. Another example would be mercury which, in contact with organic material, might result in methyl-mercury, a material of in reased toxicity.

In the conservative form, the correction factor is determined by

$$
c=\frac{T I(\max )}{T I_{0}}
$$

where

$$
\begin{aligned}
& \text { TI }_{\text {max }}=\text { maximum toxicity index attained by the sum of the } \\
& \text { parent and progeny present at any future time, and } \\
& \text { TI } T_{0} \text { initial toxicity index of the parent material. }
\end{aligned}
$$

When the toxicity of the progeny never exceeds that of the parent material, $\mathrm{TI}_{\max }=\mathrm{TI}_{0}$ and $\mathrm{C}=1.0$. Figure 3.4 illustrates the concept. 


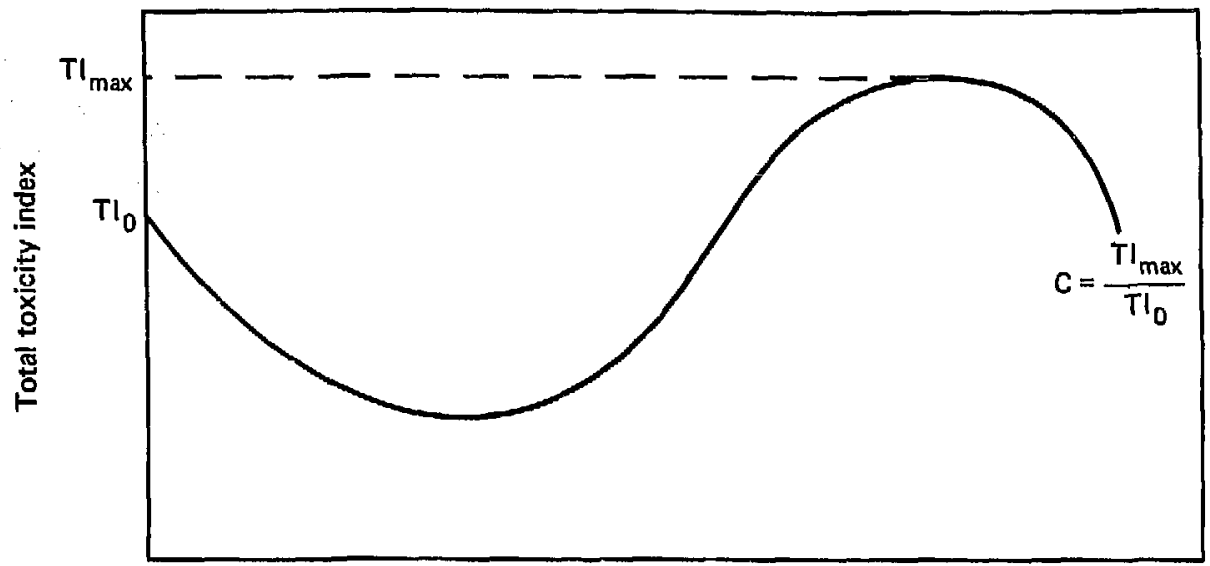

Time

Flgure 3.4 Conceptual determination of bulldup correction factor (C)

Note that where there is a algnificant alteration in the availability of decay or transiormation products, this could be reflected In the avallability factor (A). C is primarily Intended to accommodate the buildup of toxicity and the extension of persistence as a regult of decay-pronuct buildup. The correction factor (C) may also be used to rectify special cases where unusual or unforeseen circumstances may significantly alter the overall geotoxic hazard.

\subsection{DISCUSSION}

In this section, a geotoxic hazard Index has been developed by applying conservative approximations and simplifications to a theoretical 
measure of hazard. The form of the hazard index for material 1 is

$$
\mathrm{GHI}_{1}=\mathrm{TI}_{1} \cdot \mathrm{P}_{1} \cdot \mathrm{A}_{1} \cdot \mathrm{C}_{1}
$$

where $\mathrm{TI}_{i}$ is the intrinstc toxicity of the material and $P, A$, and $C$ are dimensionless modifiers which adjugt the toxicity to Incorporate persistence (time effects), avallability (transport potential), and decay-product bulldup, respectively.

The Intrinsic toxicity is determined by the quantity of toxic materlal and its speolfic toxicity, based on standards established for public dr Inking-water gupplies.

The persistence factor (P) Is based on the mean quantity of the toxic material in existence over a reference 300-year period. This period is used only as a basis to judge persistence and does not Involve assumptions of exposure at any particular time before or after that period. The perslstence factor is related to the half-life of the material and takes a value of 1.0 for stable or long half-life material, with gmaller values for materials whose toxiclty is shorter lived. The availability factor (A) relateg the eventual human Ingestion of the toxic material to the quantity incorporated in the earth'g crust. Th1s overall transport potential is based on values measured for naturally cccurring materials with a modiflcation factor to account for devlations from the naturally occurring analog as a result of such factors as material form, depth, hydrology, etc.

The buildup correction factor (C) accommodates phenomena that result In increaged toxlcity (e.g., decay product bulldup) for cases where the decay progeny are more toxic than the parent muterial. 


\subsection{SAMPLE APPLICATIONS}

\subsection{INTRODUCTION}

To 1llustrate the use of the geotoxicity hazard index derived in the previous section, it is ingtructive to apply the Index to some sample toxic-materlal inventorles. This section includes a description of aample inventories representing a low-level radioactive waste facility, a high-level repository, a reference uranlum ore body, and two stable metal ore depositB. In addition, simplifying assumptions used for the calculations are discussed. The results for each sample problem are described and analyzed in light of the Insights which result from the use of the geotoxicity hazard Index. The detalled numerical data (MPC' 8 , Dhs's, $P, A_{0}, C$, etc.) for the materials included in the inventories are given in Appendix $B$.

It should be noted that the reference facilities described are consldered reasonable examples and are not intended to reflect any actual sites or operations. The discussion is presented primarily to demonstrate the methodology and to provide some insight into the nature of the calculational results,

\subsection{DESCRIPTIONS OF SAMPLE INVENTORIES, ASSUMPTIONS, AND RESULTS}

\subsection{A Low-Level Waste Facility}

The reference containment facility (RCF) described in a Ford, 
Bacon and Davis Report (1977) is used to simulate a large, low-level waste facility (LWW). The reference site includes the significant radionuclide inventories resulting Erom $1000 \mathrm{GW}(\mathrm{e})$ years of power production. Table 4-1 lists the assumed parameters related to the facility, and Table 4-2 lists the radionuclide inventories present in the facility, together with the computed nuclide geotoxicity hazard indices and the total index.

Table 4-1. Reference containment-facllity parametera.a

Capac1ty:

$6 \times 10^{5} \mathrm{~m}^{3}$

(Sufficlent volume to contain the wastes generated by 1000 GW(e) yr of power production)
Site plan área:
$2 \times 10^{6} \mathrm{~m}^{2}$
Size of trenches:
$200 \mathrm{~m} \times 10 \mathrm{~m} \times 8 \mathrm{~m}$
Number of ptta:
100
Distance to site boundary: $160 \mathrm{~m}$

aDats from Ford, Bacon, Davis (1977).

Table 4-2. Low level waste Inventorieg and GHI.

\begin{tabular}{lcl}
\hline & $\begin{array}{c}\text { Reference } \\
\text { inventory } \\
\text { Strontium-90 }\end{array}$ & $\frac{\text { GHII }}{(C 1)}$ \\
Iodine-129 & 0.73 & $5.54 \times 10^{10}$ \\
Cesium-137 & 35000 & $9.87 \times 10^{7}$ \\
Neptunium-237 & 12000 & $1.14 \times 10^{8}$ \\
Plutonium-239 & 65000 & $1.98 \times 10^{11}$ \\
Amer Icium-241 & 65000 & $8.45 \times 10^{9}$ \\
Total GHI for the facility & $8.22 \times 10^{9}$ \\
\hline
\end{tabular}


For the index calculation, the values for $T$ (specific toxicity), $P$ (persistence), $C$ (builoup correction), and $A_{0}$ (availabllity, as in nature) are listed in Appendix B. The modification factor (m) for $A_{0}$ ' is taken as unity to reflect the simplifying assumption that, in our reference facllity, the nuclides are, for present purposes, considered no more or less available than their naturally occurring analogs (occurring within 12 meters of the surface). A more detalled analysis, including leach rates, sorption characteristics, local hydrology, etc., could provide more precise values for $\mathrm{m}$.

From the results shown in Table 4-2, and the additional data in Appendix B, it is interesting to note the importance of Np-237. This isotope represents the largest component of tine total GHI; by evaluating the factors in GHI, we see that this is due primarily to the large initial toxicity and to a significant buildup correction factor.

\subsubsection{A Reference High-Level Waste Repository}

For the purpase of defining a reference high-level waste (HLW) Repository, we used values published in NUREG-0279 (J. J. Cohen et al., 1977) For the waste inventory due to light-water reactors. To simplify the calculations, we assumed the inventorles due to $1000 \mathrm{GW}(\mathrm{e})$ years of power production are placed in a repository after a 10-year holding period. Table 4-3 lists some of the parameters assumed for the simplified fuel cycle, and Table 4-4 lists the inventorles and GHI values of some of the more important components, together with the total GHI for the entire inventory. 
Table 4-3. Fuel-cycle parameters for high-level waste.a

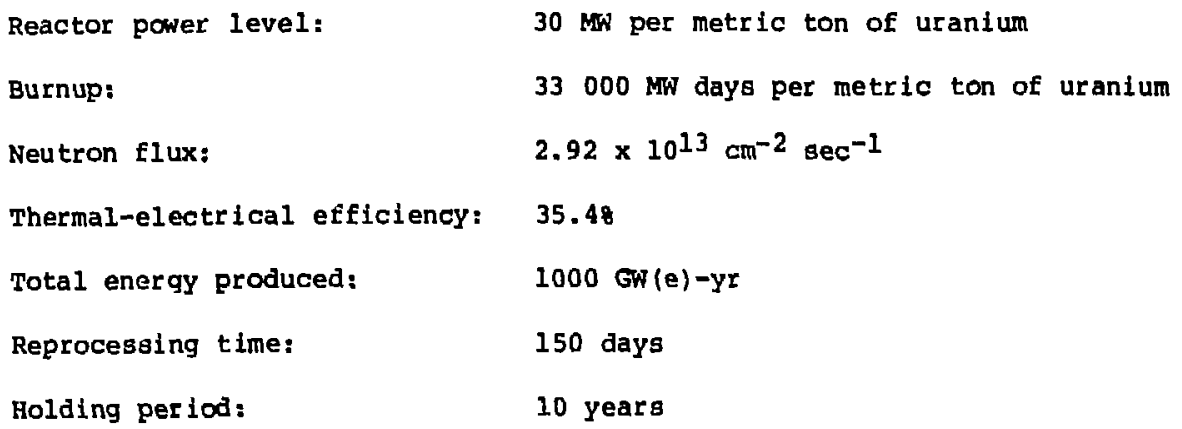

a (Data from NUREG-0279, J. J. Cohen et al., 1977)

Table 4-4. High-level waste inventories and GHI.

\begin{tabular}{|c|c|c|}
\hline & $\begin{array}{c}\text { Reference } \\
\text { inventory } \\
\text { (ci) }\end{array}$ & $\mathrm{GHI}_{1}$ \\
\hline Stront 1 um-90 & $1.9 \times 10^{9}$ & $4.39 \times 10^{13}$ \\
\hline Technet I um-99 & $4.4 \times 10^{5}$ & $9.46 \times 10^{8}$ \\
\hline TIn-126 & $1.7 \times 10^{4}$ & $1.89 \times 10^{9}$ \\
\hline Cest un-134 & $2.6 \times 10^{8}$ & $1.29 \times 10^{9}$ \\
\hline Ces1 um-137 & $2.7 \times 10^{9}$ & $8.51 \times 10^{10}$ \\
\hline Europi um-154 & $1.4 \times 10^{8}$ & $8.82 \times 10^{9}$ \\
\hline Plutonium-238 & $3.2 \times 10^{6}$ & $1.59 \times 10^{9}$ \\
\hline Amer 1 cium-241 & $5.5 \times 10^{6}$ & $7.06 \times 10^{9}$ \\
\hline Curium-244 & $5.4 \times 10^{7}$ & $4.36 \times 10^{9}$ \\
\hline Total GHI & & $4.40 \times 10^{13}$ \\
\hline
\end{tabular}


Once again, values for T, P, C, $\quad{ }^{l_{0}}$ are listed in Appendix B; however, $m$ l.s arbitrarily assigned the value $0.0^{\prime}$ to reflect the expectation that, with properly engineered waste ns and repository design, together with an intelligent choice for siting, and at great burial depth, one should expect a significant improvement in preventing the avallability of the toxic components of high-level wastes, compared to the average values for their naturally occurring counterparts in the top 12 meters. A more detailed study of the factors affecting availability could provide more precise values for $m$. The value of $m=0.01$ as used here is probably conservative (pessimistic), and the reaulting GHI may therefore be considered a high estimate.

The relative importance of strontium-90 regulta from the fact that, although its persistence is low, its initial inventory and specific toxicity are relatively large. of course, the actual inventory could never be as large as 1000 times the inventory due to a single 1000 MWe-year of operating power, since the assumed 1000 GWe-years of production would be spread out over many years, allowing for considerable radioactive decay of this 30 -year nuclide.

\subsubsection{A Reference Uranium Ore Body}

A uranium ore body that is one $\mathrm{km}^{2}$ area by 10 meters thick and that contains 0.28 uranium is considered a reference ore body. Toxic radioactive and nonradioactive heavy metala, other than those involved in the U-238 decay chain, are ignored for simplicity. The contents of the reference ore body are assigned values of $m=1$ to correspond to the 
assumption that these materials, as emplaced in the ore body, behave in a manner typical to that of the average of other naturally occurring, near-surface urani im decay-chain materials. Levels of lead in the uranium ore deposit are based on values for the Colorado plateau region (Finch, 1967).

Table 4-5 summarizeg the inventory and geotoxicity hazard index computations for the reference ore body. It is particularly interesting to note the prominence of the uranium isotopes. Although the isotopes have low values for specific toxicity and availability, their bulldup correction factors are quite large. This is due to radioactive decay daughterg, and to the eventual buildup of stable lead-206, a highly toxic metal. The greatest contribution to GHI is seen to be that of Ra-226, the most toxic decay-chain component.

Table 4-5. Reference uranium ore body.

\begin{tabular}{lll} 
& \multicolumn{1}{c}{ Inventory } & GHI \\
Uranium-238 & $1.68 \times 10^{4} \mathrm{CI}$ & $5.2 \times 10^{11}$ \\
Thot ium-234 & $1.68 \times 10^{4} \mathrm{CI}$ & $3.8 \times 10^{4}$ \\
Uranium-234 & $1.68 \times 10^{4} \mathrm{CI}$ & $2.5 \times 10^{11}$ \\
Thorium-230 & $1.68 \times 10^{4} \mathrm{Ci}$ & $2.5 \times 10^{11}$ \\
Radium-226 & $1.68 \times 10^{4} \mathrm{Ci}$ & $1.8 \times 10^{12}$ \\
Lead-210 & $1.68 \times 10^{4} \mathrm{Ci}$ & $1.8 \times 10^{11}$ \\
Polonium-210 & $1.68 \times 10^{4} \mathrm{Ci}$ & $6.0 \times 10^{7}$ \\
Lead (Stable) & $8.19 \times 10^{6} \mathrm{~kg}$ & $1.6 \times 10^{10}$ \\
$\quad$ Total GHI & & $3.0 \times 10^{12}$
\end{tabular}


It is interesting to compare the total GHI for the ore body to the index values for the two reference waste facilities. The ILW facility has a significantly lower geotoxicity hazard index than the uranium vie body, while the HIH repository appears to be of greater hazard.

\subsubsection{Reference Stable Metal Ore Bodies}

Having considered reference radioactlve waste facllitles and a uranium ore deposit, it is appropriate to compare some stable metal ore deposits. The toxicity of lead has been previously noted in coijunction with uranium decay; therefore, it is interesting to consider this metal by Itself, noting that the annual U.S. production of lead is on the order

of $5 \times 10^{6}$ tons. In addition, an ore deposit of mercury will be considered. The annual U.S. production of mercury is on the order of 1000 tons.

For the purpose of characterizing reference ore bodies, we have arbitrarily defined the reference deposit to contain an inventory equal to 108 of the current annual U.S. production. Considering recoverable and nonrecoverable fractions, ore bodies of this magnitude do not appear unreasonable. Further, $m$ is given the value of unity for these ois bodies to reflect the assumption that the availability of these materials is no better or worse than their average values for natural deposits. For stable metal ores, the persistance factor (P) is, of course, assigned a maximum value of 1.0 .

Table 4-6 summarizes the results of these calculations. The large GHI for the mercury deposit results from its high mobllity and specific toxicity. The almost equally large value for lead results from its large 
inventory and moderately high mobility and toxicity. Each of these ore bodies is roughly comparable in terms of GHI to the HLW repository and the uranium ore deposit.

One would expect to find other toxic minerals in conjunction with an ore body as considered here, particularly in the case of the lead deposit. A detailed analysis of the inventorles of typical ore deposits would be quite interesting, but would not necessarily add to the purpose of demonstrating the use of the GHI.

Table 4-6. Calculational results for stable metal ore bodies.

$\begin{array}{lcccc}\text { Ore body } & \begin{array}{c}\text { Inventory, } \\ \text { tons }\end{array} & \begin{array}{c}\mathrm{DWC}, \\ \mathrm{mg} / 1\end{array} & \text { A } & \text { GHI } \\ \text { Mercury } & 10^{2} & 0.002 & 2.55 \times 10^{2} & 1.3 \times 10^{13} \\ \text { Lead } & 5 \times 10^{4} & 0.05 & 9.68 & 9.7 \times 10^{12}\end{array}$

\subsection{DISCUSSION}

The GHI has been applied to sample cages in order to demonstrate its use. The sample cases have been defined so as to be reasonably representative, but primary emphasis has been on the application of the Index, not on the rigorous determination of toxic material inventories or other parameters. In particular, the assumed values for $m$, the availability modification factor, were chosen somewhat arbitrarily. More detalled, quantitative determinations of values for m would be highly desirable and would yield results in which confldence could be progressively increased. 
The reference LLW facility is seen to have a lower GHI than that of the HLW repository and the reference ore bodies. In some cases, the GHI has Indicaten hiọt os low contributions from particular inventory components due to moblilty, Farsistence, inventory, or specific toxicity or to some combination of these factors. This physical insight into the problem is of particular importance. A more detalled analysis based on the sample problems would be interesting and Instructive but not essential for demonstrating the use of the GHI. In addition, it would be Interesting to consider a nonradioactive hazardous waste dump for purposes of comparison. Unfortunately, reasonable estimates of hazardous waste inventories are currently unavailable. 


\subsection{SUMMARY AND CONCLUSIONS}

In this study, we have reviewed several previously suggested approaches to develop an Index of hazard related to the potential harm resulting from applications involving toxic materlals. Our objective has been to determine a suitable Index related to the hazard of toxic material buried in the earth's crust. We developed the Index to characterlze the hazard of radioactive or other toxic wastes buried underground.

Our review of previous approaches revealed thers did not extet an Index which met the above noted objective and was both aimple to use, and applicable to stable as well as to radioactive toxlc material. Consequently, the Geotoxicity Hazard Index (GHI) was developed. The GHI treats the parameters of importance as follows:

- The intrinsic toxicity of the material is guantitatively described In terms of a toxicity index (TI). The TI is a function of the quantity (Q) and Inherent toxicity of the naterlal (e.g., TI $=Q / M P C)$.

- The persistence or longevity of the materlal is described by a persistence factor (P). As formulated, P has a maximum value of 1.0 for stable elements and lower values for materlals that decay or decompose. For radloactive materials, $P$ can be determined from the half-Iife.

- The avallability factor (A) is related to the potential for transport to and assimilation of the material into human tissue.

- A buildup carrection factor (C) is applicable to those materials whose decay or transformation products are more toxic than the parent mater $1 \mathrm{al}$. 
Mathematically, the GHI is the simple product of these parameters and, for any material (i),

$$
\mathrm{GHI}_{i}=\mathrm{TI} \mathrm{I}_{\mathbf{i}} \cdot \mathrm{P}_{\mathbf{i}} \cdot \mathrm{A}_{\mathbf{i}} \cdot \mathrm{C}_{\mathbf{i}} \cdot
$$

For mixtures of various materials,

$$
\mathrm{GHI}=\sum \mathrm{GHI}_{i}
$$

The GRI can be applied to assessments of radioactive and stable toxic materfal buried in the earth elther by man or by nature. Sample calculations applied to various "reference" sites indicate the values shown in Table 5-1.

TABLE 5-1. Summary of application results.

site

Low-level waste facility

$2.7 \times 10^{11}$

High-level waste repository

$4.4 \times 10^{13}$

Uranium ore deposit

$3.0 \times 10^{12}$

Mercury ore deposit

$1.3 \times 10^{13}$

Lead ore deposit

$9.7 \times 10^{12}$

The assumptions used in calculating the above values may be found in the section 4 and Appendix B. Note that the parameters were derived by cursory means and are not intended to denote a precise relationship. The 
calculations were performed primarily to demonstrate the application of the GEI, and the results may be considered first approximations. Further refinement of the input parameters, partlcularly the availability factor (A), will yield results that permit increasing confidence. Application of the GRI concept in 1 ts present form cannot indicate absolute hazard or risk. Absolute risk can only be predicted by using systems analysis methods that incorporate the best available parametric data. The GHI can be useful, however, in evaluating relative hazard and, as such, can be helpful for the declsion-making process to select alternative methods of waste management, and to determine criteria for acceptaible risk. Ideally, an index of relative hazard should be completely dimensionless and related to a given standard. Making the GHI dimensionless would likely increase its understandability and applicability. Future work will be devoted to achieving this objective. 


\section{APPENDIX A. A REVIEW OF INDICES DEVELOPED TO MEASURE ENVIROMENTAL HAZARDS}

\section{A.1 INTRODUCTION}

To provide a framework for development of a geotoxicity hazard index, we conducted a review of previously proposeä indices developed to quantify the risk or hazard assuciated with some material or acsivity that may have a deleterious effect on human health or the environment.

A simple example illustrates the distinction between lisk and hazard. The hazard of crossing the ocean in either a raft or a modern ovean liner is the same-drowning. However, the risk in each case is quite different, being dependent on the probability of the hazard occurring. For the purposes of this study, a hazard measure or index is a quantity assoclated with the potential consequences of any activity involving toxic chemical or radioactive material, while a risk index or measure is associated with both the potential adverse cousequence and the probability of its occurrence. These definitions, however, are not always applied rigorously in this appendix; the first priority in using notation is given to employing the terminology used by the author of the cited publication.

For Indices developed to deal with the hazards of radiotoxic materials, we have attempted to make the most comprehensive catalog possible. For general environmental and nonradioactive toxic indices, we have considered a representative sample to describe the spectrum of available $\_\infty o l s$. This was done for two reasons. First, the principal overall objective of this project was to determine or develop an index appropriate for radioactive waste 
disposal and extendable to nonradioactive hazardous waste materials. Second, the number of nonradiotoxic environmental indicators and indices proposed previously is too large to allow for detailed review in this study. A comprehensive review of environmental indicators may be found in the 1971 MITRE Study (Bissell, 1971). Other comprehensive hazard index reviews have been carried out by Voss (1979) and Poston (1978).

\section{A.2 GENERAL QUALITIES OF ENVIRONMENTAL INDICES AND MEASURES}

It is apparent that no single index is completely defensible. What is required in most cases is a quantitative index consistent with scientific fact and informed opinion. Varlations in the structure and value of different indices are, therefore, to be expected.

Environmental indicators of risk and hazard can be classified both according to their construction and to what they are designed to measure. In this study, the major division is according to radiotoxic and general environmental indicators. The radiotoxic indicators are further divided into four categories:

(1) Simple indices based on quantity.

(2) Toxic indices that account for both quantity and toxicity.

(3) Complex indices that account for quantity, toxicity, and physical propertiea.

(4) Complex indices that consider quantity, toxicity, physical properties, and value judgement. 


\section{A.3 INDICES AND MEASURES DEVELOPED FOR USE WITH RADIOTOXIC MATERIALS}

\section{A.3.1 Simple Indices}

The most basic measure of hazard from a radiotoxic substance is "Q," the quantity of material present. $Q$ may have units of mass (grams), activity (curles, disintegrations per second), or number of atoms. Of itself, the quantity of toxic materlal does not provide a satisfactory measure of hazard. However, it is a necessary ingredient for every index of toxic hazard.

The quantity, $Q$, of toxic material also yields other simple indices such as volume, or concentration. One example of the use of volume as an Index is the statement that the solldified high-level radioactive wastes produced in generating all the electricity used by a v.s. citizen in a year are comparable in volume to an aspirin tablet. The aspirin-tablet comparison has been attributed to Starr and Hammond (1972).

Another simple index based on the quantity of radioactive material is the so-called "Hiroshima Index," 1.e., that the material contains as much radioactivity as $x$ Hiroshima bombs. This index has been used frequently in nuclear debates.

It should also be noted that the thermal energy resulting from decay heat in fission-product waste can be viewed as a type of index of hazard, though an indirect one.

The tota]. $Q$ (as curies, grams, gram-atoms, watts) in various phases of the nuclear fuel cycle is of ten calculated with the computer code ORIGEN (Bell, 1973). The ORIGEN code is a point-depletion code that solves the 
$500 \mathrm{rem}$. As the whole-body dose approaches 1000 rem, fatalities reach 1008. However, most environmental releases of toxic materials result in small exposures over 2 extended period of time. A toxicity index based on lethal cose is not completely appropriate for these types of exposures.

Maximum Permissible Concentration. The concept of maximum permissible concentration (MPC) is that a standard can be set which results in an acceptable exposure to a radiotoxic material. MPC is a specified concentration (such as curles per cublc meter) in air or water. The maximum permisaible concentration (NBS, 1959; EPA, 1975; IAEA, 1967, 10CER 20, 1959; ICRP, 1964) or the relatad radiological concentration guide (RCG) and the maximum permissible intake (MPI) can be considered basic toxicity measures. One or both of these measures occurs in many radiotoxic measures and Indices. MPCs have been published by the International Comunission on Radiological protection (ICRP) and by various national and advisory bodies; they include values for air and water, for soluble and insoluble forms, and for occupational and public exposure. The RCG is related to MPC and has a comparable meaning and units. In this review, the term MPC is used for consistency.

MPCs were originally intended as guidelines for maximum concentrations that would keep radiation doses to workers in nuclear facilities at levels well below the level at whlch damaging effects were predicted to occur. Occupational MPCs, based on exposures of 40 and 168 hours per week, were then derived from their annual dose-rate limits. In addition, the MPCs for each 1sotope are based on the energies, penetrating power, and relative biological effectiveness of the emissions from radioactive decay of the 
lsotope, on the pathways and residence times of the isotope within the body, and on these same determinants of dose from radioactive daughters produced by decay of the original isotope while Inside the body. In these derivations, 1sotope intakes were related to environmental concentrat:ons by means of a "standard-man" model specifying the volume of air inhaled and the volume of water ingested per day or per 8-hour working day. The MPCs obtained by these procedures generally do not account for such indirect pathways to human intake as the accumulation of a radioactive isotope in a chain such as fallout $\rightarrow$ grass $\rightarrow$ cow $\rightarrow$ milk $\rightarrow$ human. The MPC for nonoccupational (public) exposure is generally obtained by dividing the permissible occupational exposure by a factor of 10 to arrive at values appropriate to the general population.

The MPC concept is analagous to two other standards that have been used for nonradioactive toxic materials: the "drinking-water standard" (EPA, 1975) and the "threshold limit values" (ACGIH, 1978) for airborne concentrations. Drinking-water standards correspond to concentrations of toxic chemicals in drinking-water supplies that are judged to be the maximum levels consistent with a safe supply of public drinking water. The threshold limit values represent the alrborne concentration of substances that provide a reasonably safe environment for continuous exposure (40-hour week) for nearly all workers.

Maximum Permissible Intake. The maximum permissible intake (MPI) is defined as the product of the MPC and the annual consumption rate for air or water, depending on whether the MPC is for inhalation or ingestion. The "standard mann is assumed to Inhale $7300 \mathrm{~m}^{3}$ of alr per year and to ingest $0.8 \mathrm{~m}^{3}$ 
of water per year. The IAPI is defined for both soluble and insoluble forms, since the MPC is defined for both.

Another interesting varlation on this type of measure is the description of toxicity in terms of maximum permissible body burden (MPBB), as discussed by Pingel and Shipp (1976). In this article, toxicities are expressed in terms of weights, activitles, and spherical-particle diameters representing MPBB quantitles of radioactive and chemical toxins.

As measures of radiotoxic hazard, the MPC and MPI are not satisfactory by themselves. In both cases, continuous consumption is assumed, and no conslderation is given to time persistence or to pathway amplification or attenuation. However, both can be useful in assessing the safety of nuclides in at least two instances. First, when compared for different radionuclides, MPC and MPI may indicate the relative toxiclties of various materials. Second, MPC and MPI can provide fundamental input to other hazard measures and indices.

Relative Hazard. One of the first large-scale attempts at expressing the relative hazard of various zadionuclides was published by Morgan et al. (1955) in the form of relative hazard valueg for a large number of radionuclides and several exposure situations. The values were for accidental single exposures and considered only the Inhalation or ingestion of elther soluble or insoluble radioactive materlals. The authors expressed the relative hazard (H) in case of a splll or accident involving $100 \mathrm{mCl}$ of radloactive material as:

$$
\mathrm{H}=\frac{10}{(\mathrm{MPI}) \cdot(\mathrm{mg} / 100 \mathrm{mCl})} \text {. }
$$


In this equation, $10 /(\mathrm{mg} / 100 \mathrm{mCl})$ represents the likelihcod of an inhalation of $10 \mathrm{mg}$ of radioactive material, and (MPI) is the maximum permissible intake that can be calculated by equations specified in the text. The equation was based on a consideration of the maximum dust lozding of industrial air and on a determination of the average radioactivity per shipment of more than 52000 shlpments of radioactive materlal from the Oak Ridge National Laboratory (ORNL) during 1954. For conveniance, the average accident was assumed to involve a total activity of $100 \mathrm{mr} .1$. A more general form of the equation, given by these authors, $1 \mathbf{s}$

$$
H=\frac{0.1}{(M P C) \times D \times(m g / m C i)},
$$

where (MPC) is the maximum permissible concentration $\left(\mu \mathrm{cl} / \mathrm{cm}^{3}\right)$ in the medium, D ig the daily intake of the medium, and $0.1 /(\mathrm{mg} / \mathrm{mCl})$ represents the possibility, $P$, of inhalation of a given guantity of the $r$ udionuclide. When the value of $\mathrm{mg} / \mathrm{mcl}$ is less than $0.1, P$ is set equal to 1 .

Later Morgan and his colleagues (1964) published the results of additional calculations, utilizing the term "relative hazard." In this case, $\mathrm{H}$ was given for varlous radionuclides under uniform working conditions. For convenience in this comparison, ${ }^{226}$ Ra was taken as the reference atandard. In other words, the relative hazard, $\mathrm{H}$, is equal to 1 for ${ }^{226} \mathrm{Ra}$. The general equation for the relative hazpid in this case $1 \mathrm{~B}$

$$
H=\frac{2.92 \times 10^{-11} \phi(C 1 / q)}{\text { MPC }}
$$


where MFC is the maximum permissible concentration in the particular medium and $\phi(\mathrm{Ci} / \mathrm{g})$ is a function of the specific activity $(\mathrm{Cl} / \mathrm{g})$ of the radionuclide. For simplicity, it was assumed that $\phi(\mathrm{Cl} / \mathrm{g})=\mathrm{Ci} / \mathrm{g}$ if $(\mathrm{Cl} / \mathrm{g}) \leq 10$ and $\phi(\mathrm{Cl} / \mathrm{g})=10$ if $(\mathrm{Cl} / \mathrm{g})>10$. Note that, for $\mathrm{H}=1$ and $(C 1 / g)=1$, the MPC for ${ }^{226} \mathrm{Ra}$ is about $3 \times 10^{-11} \mu \mathrm{Ci} / \mathrm{cm}^{3}$, which corregponds to the (MPC) air for the soluble matertal as given by the International Commigsion on Radiological Protection (ICRP, 1959).

Hazard Index. One of the elementary hazard measures involving a combination of parameters is widely designated the "hazard index." Hilliar (1968) appears to be the first to use this measure. The hazard index of a radionuclide $i, \mathrm{HI}_{1}$ is defined as

$$
\mathrm{HI}_{i}=\mathrm{Q}_{i} / \mathrm{MPC}_{i^{\prime}}
$$

where $Q_{1}$ is the quantity of material $i$ in curies and $\mathrm{MPC}_{1}$ is the maximum permissible concentration (in air or water) in curies per cubic metre. Thus, the units of $\mathrm{HI}_{1}$ are cubic meters of air or water. As such, the hazard index can be interpreted as the quantity of alr or water required to dilute a given quantity of radioactive material to its MPC value.

The hazard index for a collection of $\mathrm{N}$ radionuclides is given by

$$
\text { HI }=\sum_{1=1}^{N} \mathrm{Q}_{1} / \mathrm{MPC}_{1} \text {. }
$$

Note that the hazard index for radionuclides is a time-dependent quantity. In reviewing the hazard Index as a means of assessing waste 
management safety, Voss (1979) concluded that the hazard measure, HI, can be both useful and misleading since it does not consider all relevant factors. Factors not considered include the probability that sources will release radioactive material into the biosphere, the mobility of the radionuclides, and the degree of local concentration of the radioactive sour ces.

The Modified Hazard Index. Another index based on the Q/MPC ratio is the modified hazard index (HI). This is indeed an index, for the ratio Q/MPC is divided by a volume. The definition of this hazard index is

$$
\mathrm{HI}_{1}=\mathrm{Q}_{1} /\left(\mathrm{MPC}_{1} \times \mathrm{V}\right)
$$

and

$$
\mathrm{HI}=\sum_{i=1}^{N} \mathrm{HI}_{i} \text {, }
$$

where $\mathrm{V}$ is a contic volume in which the waste is initially diluted $\left(\mathrm{m}^{3}\right)$. The modified HI can be interpreted as the number of times a given volume of waste would have to be diluted to achieve MPC.

This index has been used to examine various aspects of radioactive waste management. ialborne (1975) used the modified HI to examine the benefits of actinide renoval from high-level wastes. The modified HI may be calculated for specific radionuclides and for total Inventories generated in any fuel cycle.

The principle disadvantage of this index is that--while it predicts the numbers of dilutions-it does not reveal anything about the pathways 
or probability of dilution. It also relates to relative concentrations, rather than absolute quantities. For the chronic, low-dose exposures considered related to underground waste disposal, concentration is a far less relevant factor than is total inventory.

Number of Lethal Doses. In an overview on hlgh-level radioactive wastes, B. L. Cohen (1977) presented a potential hazard index that can be referred to as "number of lethal doses." This index 1s based on the observation that all the information needed to calculate the dose to various body organs per curle of radioactive material ingested is included in the MPC. This derives from the fact that the MPC is defined as the concentration of an lootope in water or air (curles per cubic meter) such that standard inhalation or ingestion would result in a dose commitment $d_{j}$ to body organ $j$, where $d_{j}$ is 130 rem for bone or thyroid, 15 rem for lungs, kidneys, gastrolntestinal tract, etc." Based on this observation, the number of lethal doses per year from isotope 1 to organ $j, D_{1 j}$, is given by the expression

$$
D_{i j}=\frac{Q_{i}}{\operatorname{SPC}_{1 j_{W}}} \times d_{j} \times r_{j} \times p,
$$

where

$$
\begin{aligned}
Q_{i}= & \text { quantity of nuclide } 1 \text { per unit mass of spent fuel } \\
& (\mathrm{C} i / M T), \\
\text { MPC }_{1 j_{W}=} & \text { maximum permissible concentration of isotope } 1 \text { in } \\
& \text { water for ingestion dose to organ } j, \\
d_{j}= & \text { dose to or yas } j \text { resulting from one year's } \\
& \text { consumption of water with } 1 \text { MPC of } i \text { (rem), }
\end{aligned}
$$




$$
\begin{aligned}
& r_{j}=\text { lethal cancer } r i s k \text { per unit dose to organ } j \text {, and } \\
& P=\text { mass of spent fuel produced annually (MT/Yr) }
\end{aligned}
$$

A similar expression is employed for inhalation, with $M_{P C} f_{W}$ replaced by the maximum permissible concentration in air, MPC ${ }_{1 f_{a}}$.

To calculate the total number of cancer deaths per year for all radionuclides in epent fuel and for cancers in all body organs, $D$, the following summation would be formed:
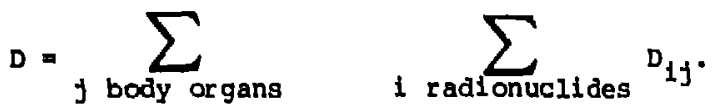

This Index was employed by B. L. Cohen (1977) to demonstrate that the cancer potential of radioactive waste, while quite high, is less than that of all the uranium produced annually in che U.S. and less than that of the annual mined quantities of many natural elements used by humans, such as lead, arsenic, and selentum.

The number of lethal doses is a measure of potential toxicity, not hazard, in that it provides no information on release rates, pathways, dissolution rates, hold-up times or other factors that would reveal the actual nature of the risk. It simply translates the basic $Q / M P C$ Index into potential deaths. It is notable, though, as an Index that does provide for comparison between nuclear and nonnuclear toxic materials, since the numbers of lethal doses are also calculable for nonradioactive toxic materials. 
Relative Toxicity Index. The relative toxicity index (RII) is defined as the ratio of the hazard measure for a man-made materlal to that of its initial ore or to some other acceptable toxic material. This index was proposed by flamstra (1975), who used it to compare the hazards of radioactive wastes to those of the uranium ore used to produce the reactor fuel.

$$
\text { RTI }=\frac{\sum_{i}\left(Q_{i} / M_{1}\right) \text { waste }}{\sum_{j}\left(Q_{j} / \text { MPC }_{j}\right) \text { equivalent uranium ore }} \text {. }
$$

A more general use for the RTI is to compare the hazards of nuclear materials to some other toxic material, either radioactive or nonradioactive. For example, Tonnessen and Cohen (1977) used the RTI to compare the time-dependent toxicity of nuclear waste to that of average mineral ores of guch toxic elements as uranium, lead, and chromium. In this instance, the RTI takes one of two forms, elther

$$
\text { RTI }=\frac{\sum_{i}\left(Q_{i} / M^{\prime} C_{i}\right) \text { waste }}{\sum_{j}\left(Q_{j} / \text { MPC }_{j}\right) \text { element as comparative base }}
$$

for a radioactive base or

$$
\text { RTI }=\frac{\sum\left(Q_{i} / M_{1}\right) \text { waste }}{\sum\left(Q_{J} / \text { DWS }_{f}\right) \text { nonradiotoxic comparative base }}
$$

for nonradioactive materlals, where DWs equals the drinking-water standard in grams per cuble meter. 
The concept behind this index is to put the radioactive waste problem in perspective by relating the hazard of a radioactive waste repository to that of naturally occurring mineral formations. The basis for comparison derives from a consideration of safe drinking-water levels. This comparison is based on the premise that the DWS and MPC are both maximum concentrations to which continual exposure of the general public does not entall undue risk to human health.

\section{A.3.3 Radiotoxic Indicators Based on Quantity, Toxic Character, and}

\section{Physical Properites}

Two characteristics of radioactive waste have not been incorporated into the hazard indicators reviewed thus far: that they are self-reducing in time through radioactive decay and that they are not readily available as a soluble form in drinking-water supplies. In this subsection we review hazard Indicators that, based on the "Q/MPC" hazard measure, attempt to build in more information by incorporating time behavior, physical properties, and site data.

The Potential Hazard Index. Gera and Jacobs (1971, 1972) introduced the potential hazard index" (PHI) in order to compare the potential hazards to mankind of several nuclides having long half-lives. This measure is defined as

$$
\mathrm{PHI}_{i}=\frac{P_{i} \cdot Q_{1}}{\operatorname{MPI}_{i}} \cdot \frac{P_{1}}{0.693},
$$


where

$$
\begin{aligned}
\mathbf{Q}_{i} & =\text { activity of nuclide } i(\mu \mathrm{C} i) \\
M_{i} & =\text { maximum permissible annual intake }(\mu \mathrm{C} i) \text {, and } \\
\mathbf{T}_{i} & =\text { radioactive half-life of nuclide }
\end{aligned}
$$

$P_{i}$ is a factor that depends on the biological avallability of the radionuclide once it is dispersed into the environment and on the reliability of the waste containment. It represents the probability of the nuclide leaving the disposal site and reaching humans. Because Gera and Jacobs were not able to determine the probability of exposure, they assigned $P$ a value of 1 for all nuclides.

Gera and Jacobs (1972) interpreted $Q_{I} / M P I_{i}$ as the number of maximun permissible annual intakes of nuclide $\underline{i}$ present in the waste. $T_{1} / 0.693$ is interpreted as the mean life and is a measure of the time span dur: " which the radionuclide will exist. Two PHI values were obtained, ine for ingestion and one for inhalation; these values can differ by up to four orders of magnitude. The relative importance of these values was not assessed.

McGrath (1974) noted that the potential hazard index of Gera and Jacobs can be viewed as being proportional to the time integral of the hazard index (HI) multiplied by a constant to convert MPC to MPI. Of course, this would assume simple decay, no decay daughters, and time-integration limits of zero and infinity (Smith and Kagtenberg, 1976).

The PHI presents some problems in its application. The authors have essentially left unspecified how biological availability should be determined. In addition, this measure tends to overemphasize the hazards 
of long-lived radionuclides. It should be noted that PHI goes to Infinity for stable elements, which indicates a problem with the approach since stable elements can not be considered infinitely hazardous. However, accommodating this objection requires that some time period of concern be specified. What time period should one be concerned about-10 years, 100 years, a million years? An tzamole of this problem has been described by Smith (1975) in the application of the PHI to LWR wastes. The fission product PHI for ingestion is dominated by neodymium-144, a mildly radioactive isotope that has a half-life of $2.1 \times 10^{15}$ years, yet is one of the least hazardous of all radionuclides. (Converted to mass units, the $\mathrm{MPC}_{\mathrm{w}}$ would require a concentration of $59 \mathrm{~kg} / \mathrm{l}$ ).

A more complete expression for the potential hazard measure was also presented by Gera and Jacobs (1971). This relation takes the form

$$
\mathrm{PHI}=r \cdot Q \cdot \frac{T}{\ln 2}\left[\frac{a}{M P I_{\text {Inh }}}+\frac{b}{M P I_{\text {ing }}}\right]
$$

where

$r=$ the reliability of the containment of radioactive materials,

$Q=$ the activity of the radionuclide in curles,

$T=$ the radioactive half-life of the materlal, and

$a, b=$ factors representing the biological availability for probability of intake) of the materlal for inhalation and ingestion, respectively.

The major difference between this measure and the previous one is that it specifies the manner in which the measures for ingestion and inhalation 
should be combined; however, determination of proper values for factors a and b could pose a difficult problem.

Smith's Modified Hazard Index. After considering some of the problems with the PHI of Gera and Jacobs, Smith (1975) developed a modified hazard index to provide "a flexible measure of hazard that permits a reasonable emphasis on the nuclide lifetime as well as consideration of decay chains and the time behavior during bulld-up and decay." The general formula for Smith's hazard index is

$$
H(t, d)=\sum_{j} \int_{t}^{t+d} Q_{f}\left(t^{\prime}\right) / M P I_{j} d t^{\prime},
$$

where

$$
\begin{aligned}
Q_{j}= & \text { activity of nuclide } j \text { as a function of time }(C i), \\
M_{j}= & \text { maximum permissible annual intake of } j \text { (ci/year) for } \\
& \text { either ingestion or inhalation, } \\
j= & \text { an index that permits sumation over the given } \\
& \text { nuclide and } i \text { ts radioactive daughters, and } \\
d= & \text { a time interval of concern for a radioactive release. }
\end{aligned}
$$

The time $(t)$ is interpreted as tine time at which the material is released to the environment, and $d$ can be used as the time incerval of concern for enviromental persistence. This, of course, makes d dependent on the nature of the problem being considered. After selecting a value for $d$, it is possible to calculate $1 \mathrm{t}$ as a continuous function of t. In his analysis of waste disposal, Smith used 100,5000, and 500000 years and infinity as values for $d$. 
The important features of this hazard measure are that it takes into account multiple decay schemes and conditions of buildup and equilibrium as well as simple decay and that it allows the time period of concern to be specifled.

The major disadvantage of the measure is that it is not clear what value of d would be appropriate; thus the value produced by Smith's measure will depend on the user's cholce of a value for d. Also, no provision is made for stable toxic elements.

Hazards Avallable Index. The basis of the hazards available (HA) Index as proposed by Bruns (1976, 1979) is that hazards to humans from any toxic substance involve two considerations--a measure of toxicity and a transport factor. The HA is a tool that enables one to determine if the correct level of lsolation has been applied to a specific toxin. If HA Is less than zero, no danger to man is foreseen. When $B A$ is greater than zero, the transport factor must be reduced.

The HA is intended to place all toxic substances on the basis of common danger to man. Thus

$$
\mathrm{HA}=\log _{10}(\mathrm{HI})+\mathrm{TF}
$$

and

$$
\mathrm{HI}=\mathrm{Q} / \mathrm{MPC} / \mathrm{V},
$$

where TF is the transport factor, HI is the hazard index, as described above, $Q$ is the quantity, and $V$ is the volume. In this index, the MPC is 
defined as the concentration one can inhale or ingest continuously without reaching a harmful effect, such as measurable life shortening. The transport factors, $T F$, are the $\log _{10}$ of the fractions of toxic substances transported through each pathway or mediun. Or,

$$
T F=\log _{10}\left[T F_{R_{1}}+T F_{R_{2}}+T F_{R_{3}} \cdots{ }_{R_{m}}\right]
$$

where

$$
\begin{aligned}
\mathbf{R}_{1} & =\text { routes to humans, } \\
m & =\text { total number of routes considered, and } \\
T_{R_{1}} & =\text { transport fraction for route } R_{1}
\end{aligned}
$$

A pathway is defined as the portion of the route to man that toxic substances take through a given medium; that is, subsurface to surface, surface to air, and air to man. Each transport route, $R_{i}$, is composed of several pathways;

$$
{ }^{T F} \mathrm{R}_{1}=\mathrm{P}(\mathrm{a}) \cdot \mathrm{P}(\mathrm{b}) \cdot \mathrm{P}(\mathrm{c}) \cdots \dddot{z}(\mathrm{n})
$$

where $P(a)$ is the fraction of the toxic substance transported by pathway $a$ and $n$ is the number of pathways being considered. Normally, the $P$ values for a given pathway are less than one; for cases of bioaccumulation, such as the bulldup of $I^{131}$ in milk, the values of $p$ can be greater than one. Each route to humans is handled separately. Although this hazard Index is rather new and difficult to employ, Bruns (1976, 1979) has applied it to several nuclear and nonnuclear technologies in order to demonstrate its use. 
Two difficulties with the HA index are that it requires detailed analygis of individual pathways and that it is based on concentration, rather than on quantities of toxic material. In addition the use of a logarithmic scale tends to obscure the physical meaning.

Enviromental Radiation Doge Commitment. The Environmental Protection Agency has proposed.a concept called the "environmental radiation dose commitment" (EPA, 1974). The ERDC concept is defined as the sum of all doses to individuals over the entire time period the material persists in the environment in a state available for interaction with humans.

It is also defined according to the expression

$$
v_{1}(t)=\sum_{n=0}^{\infty} a_{1}(t) \cdot e^{-\lambda_{1} n} \cdot T_{1}(n) \cdot F_{1} \cdot P(t+n)
$$

where

$$
\begin{aligned}
D_{i}(t)= & \text { cumulative population dose resulting from the } \\
& \text { release of radionuclide } 1 \text { in calendar year } t . \\
Q_{i}(t)= & \text { quantity of radioactive nuclide } 1 \text { released in the } \\
& \text { year } t . \\
\lambda_{1}= & \text { radioactlve decay constant. } \\
T_{1}(n)= & \text { the pethway-model conversion factor that relates } \\
& \text { the quantity of radionuclide } 1 \text { released to } 1 \text { ts } \\
& \text { concentration at the location of interest } n \text { years } \\
& \text { after release. }
\end{aligned}
$$




$$
\begin{aligned}
& F_{1}= \text { the dosimetry conversion factor that relates the } \\
& \text { concentration of radionuclides in the medium to a } \\
& \text { resultant dose to the individual exposed. } \\
& P(t+n)=\text { number of persons exposed in calendar year of } \\
& \text { release, and } n \text { is the number of years from year } t .
\end{aligned}
$$

Cumulative Exposure Index. This assessment methodology (known as CUEX) Is based on a consideration of interrelationships between environmental compartments. Because it is a site-specific index that incorporates detailed environmental modeling, it requires interaction with some set of environmental transport models or the collection of data from the site to which it is applied. The term "CuE" was Introduced by Rohwer et al. (1970). The concept embodied in this acronym was initially intended as a radiation safety guide for tranglent exposures. In its present form, the CuEx hazard index can be viewed as a quotient of exposure or doge of a radionuclide with some "selected" or "accepted" limit (Walsh et al., 1977, 1978). This hazard index is defined mathematically as

$$
H I=Q / Q_{L} \text {, }
$$

where $Q$ is the exposure or doge to the total body or to some specific organ and $Q_{L}$ is a seleoted or established limit that should not be exceeded because of a health riak to humans. The exposure modes resulting in the intake of radionuclides by man and included in CUEx are inhalation, ingestion, 
transpiration, or entry through a break or wound. This allows $Q$ to be writizen as

$$
Q=Q_{H}+Q_{G}+Q_{T}+Q_{W^{\prime}}
$$

where $Q_{H^{\prime}} Q_{G^{\prime}} Q_{T}$, and $Q_{W}$ represent components due to Inhalation, ingestion, transpiration, and entry through a wound. At a more detailed level these quantities can be calculated in terms of the environmental concentrations affecting them:

$$
\begin{aligned}
& Q_{H}=c_{A} \cdot v_{A} \cdot E_{a} \cdot \tilde{R} \\
& \tilde{R}=\int_{0}^{T} R(t) d t,
\end{aligned}
$$

where

$$
\begin{aligned}
\mathbf{C}_{\mathbf{A}} & =\text { pollutant concentration in air }\left(\mu \mathrm{g} / \mathrm{cm}^{3}\right), \\
\mathbf{v}_{\mathbf{A}} & =\text { breathing rate of the reference individual } \\
& \left(\mathrm{cm}^{3} / \text { day }\right), \\
\mathbf{f}_{\mathbf{a}} & =\text { fraction of inhaled pollutant deposited in the } \\
\widetilde{R} & =\text { cumulative retention of time } T \text { of pollutant in the } \\
& \text { reference organ (days), and } \\
\mathbf{R}(t)=\text { time dependence of the fractional retention of } & \text { pollutant in the reference organ. }
\end{aligned}
$$

The component due to ingertion is

$$
Q_{G}=\left(C_{F} \cdot M_{F}+C_{W} \cdot V_{W}\right) \cdot E_{W} \cdot \widetilde{R},
$$


where

$$
\begin{aligned}
C_{F}= & \text { average concentration of pollutant in food }(g / g), \\
M_{F}= & \text { mass consumption rate of food }(g / d a y), \\
C_{W}= & \text { average concentration of pollutant in drinking water } \\
& (g / m 1), \\
-\quad V_{W}= & \text { volume consumption rate of drinking water (ml/day), } \\
& \text { and } \\
f_{W}= & \text { fraction of ingested pollutant reaching reference } \\
& \text { organ. }
\end{aligned}
$$

The quantity due to transpiration is

$$
Q_{T}=C_{A} K f_{b} \tilde{R},
$$

where $C_{A}$ is the concentration of pollutant in the air $\left(\mu \mathrm{g} / \mathrm{cm}^{3}\right)$ and $x$ is the partition coefficient for the pollutant between the air and blood

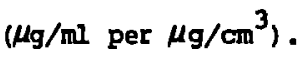

The CuEx index can also be used when one wishes to set limits for certain environmental compartment concentrations. To set an airborne concentration limit such that the organ burden $Q$ from all pathways and all routes of entry is limited to $g_{L}$, the following procedure is employed. Let $C_{A}$ equal the permitted air concentration corresponding to $\operatorname{limit} Q_{L^{\prime}}$ set $Q=Q_{L}$ in the previous equations, and solve for $C_{R}$ to obtaln 


$$
c_{A}=\frac{Q_{L_{L}}}{v_{A} \cdot f_{a}+\left(C_{F} / C_{A}\right) M_{F} \cdot f_{W}+\left(C_{W} / C_{A}\right) v_{W} \cdot f_{W}+K \cdot f_{b} \cdot \vec{R}}
$$

As given, this equation is quite difficult to evaluate. According to Walsh et al. (1977), the ratios $C_{F} / C_{A}$ and $C_{W} / C_{A}$ are not simply transfer coefficients; rather, they are ratins of concentrations of one compartment to another based on all transfer pathways. This problem is circumvented by determining a hazard index for each environmental compartment as though it were the only contaminated compartment. These hazard indices are then accumulated into a composite hazard index.

The cuEx methodology relies strongly on deterministic transport models for each material. For this reason, the cuEx hazard index cannot be employed unless one has undertaken the associated numerical calculations by means of a.set of computer codes. Further, this index is only as good as the models used to calculate dispersion in the environment.

The CuMgX index (Walsh et al., 1977) is an extension of the CUEx index to nonradioactive pollutants. It has been employed to set restrictions on cadmium emissions from copper smelters.

\section{A.3.4 Miscellaneous Indices of Radiotoxic Hazards}

This subsection presents a review of hazard indicators for radiotoxins that do not fit into the "activity-times-toxicity" framework. Moot of the Indices here were developed for very specific problems and do not have general applicability. 
Radionuclide Importance Index. The term "radionuclide Importance Index" (RII) was introduced by Leonard et al. (1969) and was developed as an ancillary portion of a larger program directed at evaluating available Information on radionuclide production in advanced reactors. This evaluation was intended to provide insight into public health concerns arising from the potential release of small amounts of these radionuclides during routine operations.

The radionuclide importance index is defined as

$$
R I I=\frac{P}{B} \times \frac{T}{t},
$$

where

$P=$ production rate of radionisclide (atoms $\left./ \mathrm{cm}^{3} . \mathrm{s}\right)$,

$B=$ biological importance factri: (disintegrations/cm ${ }^{3}$. 8).

$\tau=$ physical half-life (seconds), and

$t=$ chsracteristic time for transport and release to the environment (seconds).

The production rate factor, P, repregents the average rate at which a given radionuclize is formed (by fission and subsequent decay or by neutron absorption) In a nuclear reactor. The RII is directly proportional to $P$ since a nuclide can be of concern only if it is produced in signiflcant quantity.

The biological importance factor, B, represents the allowable exposure to a particular radionuclide for the general public, based on direct ingestion. This factor is defined as

$B=\frac{C M R}{T f_{a} \in[1-\exp (-0.693 T / T)]}$, 
where

$$
\begin{aligned}
& \text { B = biological factor (dis/s } \cdot \mathrm{cm}^{3} \text { ), } \\
& c=\text { numerical conversion constant, } \\
& M=\text { mass of critical body organ for a specific } \\
& \text { radionuclide, } \\
& R=\text { effective radius of the critical body organ (cm), } \\
& T=\text { effective half-life (years:, } \\
& \epsilon=\text { effectlve energy per decay (MeV), } \\
& f_{a}=\text { fraction of the radionuclide ingssted reaching the } \\
& \text { critlcal organ, and } \\
& \tau=\text { phyglcal half-life (years). }
\end{aligned}
$$

This factor accounts for exposure of the critical organ by direct ingestion, including consideration of the effective biological half-1ife. A higher value of this maximum permissible concentration indicates a lower level of health concern, all other factors being constant. Consequently, B appears in the denominator of the RII expression.

Radiological Environmental Concern Index. This dimensionless group (RECI) was proposed by I. E. Eckart (1971) in order to assess the relative environmental concern of radionuclides released from a hole in the cladding of defective fuel rods. This index is only a slight modification of the radionuclide importance index. The RECI is defined as

$$
\text { RECI }=C_{0} \frac{P}{B} \frac{T(1 / 2)}{T},
$$


where

$$
\begin{aligned}
C_{0} & =\text { radionuclide coricentration factor, } \\
P & =\text { production factor }\left(\mu \mathrm{Cl} / \mathrm{cm}^{3}\right), \\
\mathrm{B} & =\text { biological factor }\left(\mu \mathrm{Cl} / \mathrm{cm}^{3}\right), \\
\mathrm{T}(1 / 2) & =\text { radionuclide half-life (seconds), } \\
T & =\text { transport time (seconds). }
\end{aligned}
$$

The production factor is the time-dependent quantity of a given radionuclide existing in a specific reactor. This quantity is determined by solving the coupled set of equations that determine the buildup and depletion of various radionuclides. Eckart used the CINDER code to determine radionuelide productions in both PWRs and BWRs. The blological factor $B$ is the same as that used in the RII.

The transport time, $T$, represents the time characteristic for transport of a radionuclide from the point of formation through a series of pathways to a point of release in the environment. In Eckart's work, the fuel matrix was the point of formation and the primary coolant was considered the point of environmental release.

The radionuclide concentration factor, $C_{0}$, was Included in the RECI to account for the importance of concentration mechaniams in the food chain. However, according to Eckart, "Adequate analysis of radionuclide concentrations in the environment requires more substantial bloenvironmental information than is prusently avallable." For this reason, the concentration factor was included In the RECI but assigned a value of unity. 
Isolation Time. Voss and Post (1976) described a hazard measure that was referred to as isolation time, $T_{i}$. This measure is interpreted as the minimum time for leaching and groundwater travel for the various radionuclides to be diluted and retarded by chemical exchange reactions to reduce their concentrations to one MPC. Of course, this value will be different for each combination of sorption characteristics, dilution parameters, and radioactive waste form leaching characteristics. For each radionuclide, $T_{1}$ takes the form

$$
T_{1}=-\left[\frac{1}{\lambda_{1} I} \ln \left(\mathrm{MPC}_{1} \frac{\mathrm{V}_{\mathrm{F}}}{\mathrm{A}} \frac{\mathrm{FD}}{\mathrm{I}}\right)\right] \text {, }
$$

where

$$
\begin{aligned}
\lambda_{i} & =\text { radioactive decay constant }\left(s^{-1}\right), \\
I & =\text { ion-exchange holdup factor }\left(1+k_{D}\right), \\
V_{F} & =\text { voiume flow rate of groundwater }\left(\mathrm{m}^{3} / \mathrm{s}\right), \\
F D & =\text { factor of dilution (dimensionless), } \\
A & =\text { available leaching area of the waste form }\left(\mathrm{m}^{2}\right) \text {, and } \\
L & =\text { leach rate of the waste form (ci/s). }
\end{aligned}
$$

Calculation of $\mathrm{T}_{i}$ assumes that the parameters are constant and independent of time. The dilution factor, FD, is calculated as a volume ratio of the uncontaminated and contaminated water that mix during radionuclide transport to man. Note that a single $T_{i}$ may nct be readily calculated for a set of radionuclides.

The isolation-time concept was used to calculate the minimum time for groundwater transport to achleve MPC levels of dominant fission products in high-level waste. Calculation of $\mathrm{T}_{i}$ requires detailed definition of the waste-management system and of the biosphe-e. 
Somatic Doge Index. Laws and Rosenstein (1977) have formulated a somatic dose index for diagnostic radiology. This concept is not directly applicable to the evaluation of the geologic disposal of radioactive wastes. However, some of the parameters factored into this index could ultimately be included in a similar index for the dosimetry associated with radioactive wastes. The somatic dose index, $I_{D}$, is defined as

$$
I_{D}=\frac{\sum_{i=1}^{n} s_{i} \alpha_{i} \bar{D}_{i}}{\sum_{i=1}^{n} s_{i} \alpha_{i}}
$$

where

$$
\begin{aligned}
\mathbf{i} & =\text { designation for the organ of interest, } \\
\overline{\mathbf{D}}_{\mathbf{i}} & =\text { average absorbed dose in the organ, and } \\
\mathbf{n} & =\text { total number of organs under consideration. }
\end{aligned}
$$

The factor $s_{i} \alpha_{i}$ representa the sensitivity of an organ for the effect. $a_{i}$ relates to the absolute risks for cancer induction, and $s_{i}$ corresponds to relative severities. Application of this index requires a definitive knowledge of these two parameters.

Specific Risk Factor. The specific risk factor has been presented by Corbett and Macdonald (1978) as a simplifled tool for relating $a$ range or̈ reactor accidents to their radiological effects. This risk measure is based on a division of the radionuclide inventory of a reactor into four components:

(1) Fuel and other actinides.

(2) Gaseous fission proaucts.

(3) Other fission products, grouped according to volatility.

(4) Radionuclices ?: esent in the coolant. 
These release classes can be further divided to suit a range of accidents or a specific reactor.

The specific risk factor is built up from terms constructed to represent the hazard from releases in each of the release classes. The radiation doge to an individual inhaling a suspension of radionuclides in air is

$$
D_{j}=\sum A_{i j} B X_{1}
$$

where

$$
\begin{aligned}
D_{j}= & \text { dose equivalent to organ } j \text { (rem), } \\
\Delta_{1 j}= & \text { dose equivalent to organ } j \text { from inhalation of a unit } \\
& \text { quantity of nucl } 1 \text { de } i \text { (rem/C } 1), \\
X_{i}= & \text { concentration of each nuclide } 1 \text { in the air inhaled, } \\
& \text { integrated over the time of exposise }\left(\mathrm{Ci} \cdot \mathrm{s} / \mathrm{m}^{3}\right), \\
& \text { and } \\
B= & \text { individual's rate of breathing. }
\end{aligned}
$$

A measure of the dosimetric hazard associated w1th each of the radionuclide classes is defined to assess the significance of varying their release fractions. This measure, called the "specific dose factor," is defined by the equation

$$
H_{j}=p^{-1} \sum_{i} \Delta_{i j} \text { B } Q_{i \alpha}
$$

where

$$
\begin{aligned}
P & =\text { the thermal power of the reactor }(w) \text {, and } \\
Q_{1 \alpha}= & \text { the inventory of radionuclides in a total release of } \alpha \\
& \text { class elements. }
\end{aligned}
$$


It is assumed that low levels of radiation dosage carry a proportional risk of fatal cancer induction or serious genetic defects. Thus, the probability that an individual or his progeny will die from a iven release of radionuclides is $\sum r_{j} D_{j}$, where $r_{j}$ is the risk per unit dose to organ $j$ (death/rem). Based on this, the "specific risk index" is defined for the $\alpha$ release class as

$$
R_{\alpha}=\sum_{j} r_{j} \cdot B_{j \alpha},
$$

\section{A.3.5 Risk Measures that Include Risk Perception. In deciding about} risk acceptance, most Individuals make judgements based on their perception of risk. For example, an event that causes 100111 effects once a year might be perceived as more severe than 100 events per year, each having one ill effect. Even though the two events have the same yearly risk, judgements of severity will vary from one individual to another. In this section, we summarize two risk measures that attempt to include risk perception in a risk measure.

An Index of Hazard for Radioactive Waste. This index was developed by S.R. Watson (1978) as a risk ineasure for radioactive waste repositories. The measurement of risk and its comparison with benefits for the waste repository is achieved by assessing the probabilities for varlous consequences separately from the significance (or utility) of those consequences. 
This index has been formulated within the framework of decision analysis. It involves the use of a utility function for a particular consequence. The utility function quantifies both the magnitude of the consequence (in terms of health effects) and the judged severity of the consequence. The Index is determined by calculating the expected value of the utility function. This is done by multiplying the utility of any consequence by the probability of occurrence for that consequence and summing over all consequences or

$$
\mathrm{HIWM}=\sum_{i=1}^{N} \mathrm{P}_{1} \mathrm{U}_{1}(\mathrm{~m}, \mathrm{rp}),
$$

where

$$
\begin{aligned}
N= & \text { total number of consequences, } \\
P_{1}= & \text { probability of the } i^{\text {th }} \text { consequence, and } \\
U_{1}= & \text { utility of the } i^{\text {th }} \text { consequence, which is a } \\
& \text { function of both the magnitude, } m \text {, of the } \\
& \text { consequence and the risk perception, } r p .
\end{aligned}
$$

The consequence set must be mutually exclusive and exhaustive.

Watson's method views each possible repository design as a lottery. For ach design, there is a non-zero probability that same waste material may escape and affect health. The lottery is evaluated by assessing the probabilities for each deleterious consequence that is considered significant and then using these probabilities to calculate the expected utility. To do this, a utility function over all possible outcomes is cons tructed.

The obvious difficulty with this index ts that it is very complex. First, one must determine the consequences and probabilities for 
all signiflcant events in a waste respository (a monumental, if not impossible, task). Second, one must construct a utility function for each consequence. With the added condition that the consequence set be mutually exclusive and exhaustive, it is doubtful this risk Index will find many practical applications.

Risk-Perception Quantification Methodology. Munera (1978) has also proposed a methodology for analyzing the risk perception of individuals In a decision-making process. The unique feature of this method is that it uses a utility function that separates an individual's attitude toward a consequence into a preference Index under certitude and a measure of uncertalnty, The specifics of this methodology are quite complicated. (For details on the index, see the original paper (Munera, 1978)). However, the concept can be viewed as follows: for a given technology, there are a spectrum of consequences of magnitude $c$ which have a probability density function $f(c)$, where $f(c) \cdot d c$ is the probabiljty of a consequence in the interval dc about $c$. The expected consequence or risk is given by the expression

$$
\tilde{c}(c)=\int_{0}^{\infty} c \cdot f(c) d c .
$$

According to the utility theory, there is a function $u(c)$ that expresses an individual's attitude toward a consequence c. An individual with no risk preference will choose $u(c)=c$. A concave function represents $r$ isk aversion, and a convex $u(c)$ corresponds to risk tolerance. The expected utility of a given technology is given by 


$$
\tilde{c}(u)=\int_{b}^{\infty} u(c) \cdot f(c) d c
$$

Munera points out that, for a technology such as nuclear energy, a decision-maker's uncertainty about the consequences of an event will change the utility curve. Muneia's approach decouples consideration of the utility of consequences from an individual's attitude toward uncertainty. Individual preference for or aversion to a certain consequence is guantifled by a preference index under certainty that can be assessed by presenting deterministic cholces to the decision maker. The decision-maker's attitude towards uncertainty is consldered separately through the use of two r lsk parameters that quantify his behavior with respect to random events. Finally, the preference index and the risk parameters are combined into a new index for the evaluation of events with a continuous probability density.

\section{A.4 GENERAL ENVIRONMENTAL INDICES}

Previous discussions constdered indices to deal with quantifying risks or hazards primarily from radioactive materials and, specifically, from radioactive wastes. In this section, we will consider some general environmental indices that have been developed to quantify the extent of vartous kinds of environmental degradation. In a MITRE study (Bissell, 1971) for the Councll of Environmental Quality, 112 separate Indices dealing with environmental quality were described. We will not deal with these general indices exhaustively. However, we Intend to give a perspective on these Indices by looking at a representative set and providing some insight into the nature of environmental Indices. 
This section begins with the most general index, the Environmental Quality Index. We next consider two indices based on a ranking system; one that ranks a set of chemical hazards, the other ranks general environmental stresses. We then look at indices that consider elements of the ecosystem as Indicators of environmental stress. Finally, we consider the Index of Harm, which incorporates risk perception.

The Environmental Quality Index. The Environmental Quality Index (EQI) was devised by the Canadian Federal Department of the Environment as a means of quantifying environmental quality on a consistent national scale. This meagure has been described by Inhaber (1974).

All of the data used to carry out this measure of environmental quality are expressed as indices free from units ranging from 0 for the best possible environmental condition to increasing numbers for progressively worse environmental quality. A value of 1 generally means that an objective or standard is being met, that the index is at its highest level according to a particular scale of values, or that a certain environmental condition is equal to a national average.

The overall EQI has a hierarchial structure. It is built from four Indices canposed of subinaices that are further broken down into sub-subindices. The four subinalces used by Inhaber are; (1) Air Quality Index (Inhaber, Atmospheric Envir. 1975); (2) Water Quality Index (Inhaber, Water Research, 1975); (3) Land Quality Index; and (4) Index for Miscellaneous Aspects of Enviromental Quality. 
At the basic level, a sub-subindex is calculated directly from measured data by determining the ratio of the measured parameter $\left(e . g ., \mathrm{so}_{2}\right.$ concentration, visibility, number of toxic industries, pesticide levels, etc.) to an accepted numericai vaiue for that parameter. Data employed in these iraices have four basic requirements: they must be numerical rather than descriptive, reasonably rational and comprehensive, relative to the same time period, and comparable to a standard.

A set of sub-subinaices are combined to form a subindex by using the root mean square method

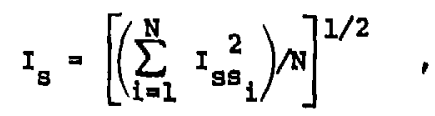

where

$$
\begin{aligned}
I_{s} & =\text { subindex vajue, } \\
I_{s s_{1}} & =\text { sub-gubindex value for parameter } 1 \text {, and } \\
N_{N} & =\text { number of sub-subindices comprising a subindex. }
\end{aligned}
$$

The root mean square method is also employed to form indices from subindices and the overall EQI from the four Indices. According to Inhaber (1974), the root mean square method n... combines the advantages of simplicity with a greater sensitivity to extreme values of environmental conditions than ordinary linear averaging." Inhaber points out that weighting may be used in the averaging process to account for more important parts of the environment or to account for population distribution.

The EOI and Its component indices may be employed on either a natlonal or regional scale. There are several advantages to this type of 
Index. The mechanics employed to carry out calculations are both simple to use and meaningful, it has a welil-defined structure, and it allows both local and regional comparisons, The major disadvantage of this Indexing system is that it requires a great deal of data collecton and, in some cases, a constant survey of expert opinion.

Chemical Hazard Ranking system. Becker (1978) has provided an algorithm that ranks chemical components of consumer products according to their probability of impact on human health. In formulating this ranking system, Becker defined several objectives he felt the system should meet. According to Becker, the system should be:

(1) Inexpensive to use.

(2) Applicable to all compounds.

(3) Able to accomodate diverse data.

(4) Easy to update.

(5) Compatible with toxicological theory.

The advantage of this ranking system is that it allows policy-making organizations to allocate resources in an optimal manner.

Becker points out that the three main factors of consumer chemical hazard due to consumer products are toxiclty, potential dose per person, and population exposed. Obviously, the risk for harm to a given population is greater for chemicals with increased toxicity, individual dose, and/or population exposure. This ranking system provides uniform techniques for estimating the factors of toxicity, dose per person and population exposed. In addition, it provides a prescription for 
calculating a hazard score from these parameters. The population exposure score $S$ is calculated according to the following procedure:

where

$$
\text { Score }(q)=s \cdot \sum_{I} p(C i) \cdot \text { 月 }\left(D / T_{1}\right),
$$

Score $(q)=$ the numerical score for the compound for the $q^{\prime}$ th effect class (e.g., carcinogenicity)--for ranking,

$S=$ the estimate of the size of the population exposed to the chemical by all producte that contain it,

$P\left(C_{1}\right)=$ the probability that the chemical belongs in the $1^{\prime}$ th toxic-strength class

$\mathbf{H}=$ a selected dose-response function,

$D=$ the mean dost to an exposed person of a chemical from

all the products that contain it, and

$T_{1}=$ the mean toxic strength of the $i^{\prime}$ th toxic-strength class.

The total score for each chemical for multiple-effect classes (i.e. carcinogens, mutagens, and teratogens) is obtained by suruning the scores for the Individual effect classes.

In constructing the ranking algorithm, Becker has defined five toxic-strength classes. The rrobability of a given compound being in each class is calculated on the basis of the experimental data avallable for that compound. The oum of these probabilities should be unity. If no such data are available for a chemical species, its probability diatribution for the five cases is assumed to be equal to the average distribution for all chemical compounds. 
The dose, D, is calculated as the internalized dose in milligrams of the chemical to the average user of the product which contains the toxic material.

The dose response function, $H$, maps ratios of $D / T$ into probabllity of response.

Although this ranking system appears to be complex, the uniformity of the mechanics allows it to be repeated with ease once it is learned, making it very compatible with small computer systems. The major Imitation of the procedure is that it is designed specifically for chemicals in consumer products. The nature of the data employed in this Index makes it Inappropriate for toxic substances buried in land fills or geologic formations.

Environmental stress Importance Index. The objective of this Index, as described by Reiquam (1971), is to establish priorities among environmental stresses. The framework behind this index is a decomposition of ecological and pollution problems Into individual environmental stresses.

The overall stress index is the product of three other indices:

$$
v_{1}=P_{1} R_{1} C_{1}
$$

where

$$
\begin{aligned}
& U_{1}=\text { atress-importance index for environmental stress } 1 \text {, } \\
& P_{1}=\text { persiotence index, ranging from } 1 \text { to } 5 \text {, based on } \\
& \text { physical and chemical properties, }
\end{aligned}
$$




$$
\begin{aligned}
R_{1}= & \text { geographical index, } \\
c_{1}= & \text { complexity index assigned according to the number of } \\
& \text { components in a system that are affected by a stress. }
\end{aligned}
$$

In this approach, two subjective assessments are made for each

environmental stress considered. The persistence index, $P_{1}$,

corresponds to the effective duration of an environmental stress. The

reactive hydrocarbon component of automobile exhaust, for example,

persists only a $f e w$ hours, while a radionuclide such as carton-14 has an

effective lifetime of several thousand years. A geographical index, $R$, between 1 and 5 is assigned according to the detectable range of environmental stress in question, as a function of the transportability and pervasiveness of sources of the stress. The persistence and range scales are shown in Table A-1.

Table A-1. Index scales for environmental assessment.

\begin{tabular}{lll}
\hline Range index & Persistence index & Index value \\
\hline Local & Days & 1 \\
Regional & Months & 2 \\
Continental & Years & 3 \\
Intercontinental & Decades & 4 \\
Global & Centur ies & 5 \\
\hline
\end{tabular}

A third index is assigned to describe the relative complexity of the impact of each stress on each of three major systems. Table A-2 shows the components of each of the systems considered. 
Table A-2 Major systems and their components.

\begin{tabular}{lll}
\hline Human & Environmental & Resources \\
\hline Biological & Land & Energy \\
Social & Air & Nutrition \\
Political & Water & Materials
\end{tabular}

The complexity index, $c_{i j}$, is assigned to each system, $j$, according to how many components in that syst:eim are affected by a given stress. Each index $c_{i f}$ takes on the value $0,1,2$, or 3 . The total complexity index $c_{1 f}$ is then

$$
c_{1}=\sum_{j=1}^{3} c_{i j} \text {. }
$$

An apparent difficulty with this index is that it tends to be overly subjective. Also, the assignment of values is quite arbitrary for each subindex. It is not clear that the difference between a local pollutant and a global pollutant or a one-day persistence versus a century's persistence can both be expressed by a 1-to-5 numerical ratio.

Biological Indices of Pollution. In this section, three indices are described that use a measure of behavior in blological systems as their basis.

R. Patriok (1971) has proposed the use of aquatic comunities as Inalces of pollution. A pollution index, in this instance, is obtained by observing population balance and diversity in aquatic systems. 
Patrick points out that the major advantage of such an index is that organisms integrate all effects that may be deleterious to the grrwth and reproduction of the species involved, while chemical analyses, which more specifically identify pollutants, give information only for substances analyzed at the point and time the collections are made.

C.S. Brandt (1971) has described observations of irivivo tissues and organs and in vitro cell cultures as a means of establishing biochemical indicators of environmental quality. An advantage of the blochemical Indicator is that information accrued in the development of these Indices increases one's understanding of the deleterious effects of pollution.

The practical use of biological indicators to monitor environmental quality has a long history dating back to the miner's canary, to the recognition of sulfur dioxide's effect on the vegetation surrounding smelters, and to the observation of how pollutants affect the population of flora and fauna living in natural waters. These indicators require the careful measurement of data. Their disadvantage as indices is their difficulty in representing subtle chronic effects in humans. In addition, they do not provide the capability needed to describe the potential hazards of unreleased toxic materials.

Index of Rigk for Inhalation Bazard. The Index of inhalation risk, as described by Ramu (1974), Is proposed as a standard for choosing the most suitable group of people to work in areas with an inhalation risk. The approach is specialized to particulate pollutants in industry. This Index is defined as the ratio of functional residual volume in the human lung to the tidal volume for a given breathing frequency. Lung 
volumes, breathing frequencies, and their influence on aeresol deposition in the lung are considered in this index.

ICRP Index of Barm. The International Commission on Radiological Protection (ICRP, 1977) provided a background discussion on appropriate measures of harm to develop an index of harm for occupational hazards. This index was intended to assess occupational safety. It was also Intended as a way of comparing radiation exposure to the hazards involved In other occupations.

In discussing an index of harm, the ICRP points out several harm criteria that might be included in an index. Death as a criterion for harm has common usage and numerous limitations. It omits consideration of nonfatal irjuries and job-related diseases. Using the number of deathe does not allow for the fact that the reduction of life expectancy is often more important than the fact of death alone. Occupational injuries as a criterion for harm should be based on the frequency and impact of injury. It is observed that the death rate, $D$, and the rate of aisabling accidents, $A$, are related according to $A \propto \sqrt{D}$. Total working days lost because of acciderts, occupational diseases, and radiation-Induced somatic effects, genetic effects, and effects during pregnancies are also included in the index. The proposed index of harm is expressed as years lost per year, per 1000 employed. It is calculated by determining how many years of a worker's life are lost from each of the above effects.

The Index of Harm. The Index of harm as described by Solonon and Abraham (1979) is an empirically derived measure of occupational risk and a means 
for comparing occupational risks across industries. The total index of harm is the sum of the risk effects of six occupational harms: three radiological harms and three are non-radiological harms. These six harms are listed in Table $\mathrm{A}-3$.

Table A-3. Types of occupational harm.

HARM
INDEX,
$j$ MARM

Nonradiological

$1 \quad$ Fatality

2 Accidental injury

3 Occupational illuess or disease

Radiological

4 Somatic effects of radiation

5 Genetic effects of radiation

6 Somatic effects of radiation to

fetus or embryo of pregnant women

The index of harm, $I$, is considered a function of $x_{i}$, the fraction of years lost in industry, 1, from any cause or event by a population exposed to those causes or events for a period of one year. A year is assumed to be 250 working days. It is also assumed that the harm contributed by each major cccupational cause is additive when measured in terms of lost work time. The index takes the form 
$I\left(x_{1}\right)=\sum_{j=1}^{6} a_{k j} \cdot n_{1 j} \cdot x_{1 j}$.

where

I $\left(x_{1}\right)=$ index of harm for the ith industry, which is a function of the fraction of yeara of logt work time;

$a_{k j}=a$ weighting factor that reflects the kth assumption (fron a set of 5) about the relative importance of work days lost from the fth harm;

$n_{i f}=$ the proportion of the occupational population in the ith industry exposed to the Jth harm and

$x_{\text {if }}=$ the number of person-years lost per 100 people in the ith industry fram the fth hasm during a one-year (250 work days) exposure.

since the rationale in selecting weighting factors is arbitrary, further development of the concept would. seem to be in order before the approach can be practically appl led in a generally acceptable manner. The problem of choosing weighting factors or utility functions is a major difflculty common to approaches incorporating perceptual factors. In general, it would seem more appropriate to first quantify hazard from a purely technical perspective and to then use the results as Inputs to the decision-making process.

\section{A.5 DISCUSSION OF EXISTING INDICES}

Previously developed indices for radloactlve and nonradioactive 
toxic materials have been described and discussed. From this review, several insights may be gained.

Many of the simple Indices of hazard developed for radiotoxic materials are, in fact, basic toxicity measures or variations on these measures. These measures focus primarily on the harm that could result from exposure to a toxic material without considering such material characteristics and processes as chemical or physical form, dilution, and transport potential. The simple indices, therefore, consider the toxic effect of a material if the material is assimilated in the body, but do not consider its potentlal Eor assimilation.

Those indices that consider avallability often do so in ways that are complex and difficult to interpret or apply. The treatment of waste characteristics and transport in a meaningful and readily applicable way would be a highly desirable extension of the previous work.

The time behavior of toxic material has also been treated by several authors. Their efforts have resulted in an arbitrary classification system for persistence (Reiguam, 1971) and in several attempts to quantitatively incorporate time factors (e.g., Gera and Jacobs, 1971). Unfortunately, some difficulty is encountered in treating stable materials with these quantitative time factors. Ideally, a persistence factor should be quantitative, nonarbitrary, and applicable to both stable radioactive materials.

A need remains for an index of hazard that effectively incorporates the factors of concern for the underground burial of toxic material. The index should incorporate time and transport factors in a way that will retain the technical meaning and yet be readily understandable and generally applicable. 


\section{APPENDIX B. DATA FOR GHI CALCULATIONS}

This Appendix contains the data used to compute the geotoxicity hazard index for the sample cases discussed in Section 4.0 (Table B-1). For each material, values are given for the approprlate water standard (DWS or MPC), half-life, $P$ (persisterice), $A_{0}$ (avallability, as in nature), and $C$ (buildup correction factor).

The DWS values are from the National Interim Primary Drinking water Regulations (EPA, 1975), and the MPC data are from IAEA Safety Series 9 (1962) except where otherwise noted.

Half-life values are from the Chart of the Nuclides (GE, 1977), and $P$ is calculated from these values according to the formula given in section 3.0.

The $A_{0}$ values are calculated from data in Cohen and Jow (1978) by dividing the ratio of intake to abundance for a particular element by the corresponding ratio for cadium. For elements not inclucled in this reference, $A_{0}$ is computed using the authors' recommended values according to their chemical grouping on the periodic table.

The bulloup correction factors were computed as discussed in section 3.0, using the Bateman equations. 
Table B-1. Data used to compute the geotoxicity hazard index in section 4.0.
Material DWS or MPC, $\mathrm{ci} / \mathrm{m}^{3}$
$\begin{array}{ll}\text { Half-life, yr } & \text { Persistance } \\ \end{array}$
Availability
factor, $A_{0}$
Correction
Factor: $\mathrm{C}$

\begin{tabular}{|c|c|c|c|c|c|}
\hline sr -90 & $1 \times 10^{-7}$ & 28.1 & $1.4 \times 10^{-1}$ & 2.7 & 1.02 \\
\hline Tc-99 & $3 \times 10^{-4}$ & $2.1 \times 10^{5}$ & 1.0 & 64.5 & 1.0 \\
\hline $\mathrm{Sn}-126^{\mathrm{a}}$ & $2 \times 10^{-5}$ & $10^{5}$ & 1.0 & 222.6 & 1.0 \\
\hline$I-129$ & $4 \times 10^{-7}$ & $1.7 \times 10^{7}$ & 1.0 & 54.8 & 1.0 \\
\hline$C 8-134$ & $9 \times 10^{-6}$ & 2.05 & $9.0 \times 10^{-3}$ & 0.45 & 1.0 \\
\hline$C \approx-137$ & $2 \times 10^{-5}$ & 30.2 & $1.4 \times 10^{-1}$ & 0.45 & 1.0 \\
\hline Eu-154 & $2 \times 10^{-5}$ & 8.2 & $3.9 \times 10^{-2}$ & 3.23 & 1.0 \\
\hline$P b-210$ & $1 \times 10^{-7}$ & 21 & 0.10 & 9.7 & 1.15 \\
\hline Po- 210 & $7 \times 10^{-7}$ & $37.9 \times 10^{-2}$ & $1.8 \times 10^{-3}$ & 1.4 & 1.0 \\
\hline $\operatorname{Ra}-226$ & $1 \times 10^{-8}$ & 2000 & 0.94 & 1.0 & 1.1 \\
\hline Th-230 & $2 \times 10^{-6}$ & $8 \times 10^{4}$ & 1.0 & 0.14 & 206 \\
\hline Th-234 & $2 \times 10^{-5}$ & $6.6 \times 10^{-2}$ & $3.2 \times 10^{-4}$ & 0.14 & 1.0 \\
\hline$v-234$ & $3 \times 10^{-5}$ & $2.5 \times 10^{5}$ & 1.0 & 0.27 & 1682 \\
\hline$U-238$ & $4 \times 10^{-5}$ & $4.5 \times 10^{9}$ & 1.0 & 0.27 & 4476 \\
\hline $\mathrm{Np}-237$ & $3 \times 10^{-6}$ & $2 \times 10^{6}$ & 1.0 & 0.65 & 79 \\
\hline Pu-238 & $5 \times 10^{-6}$ & 86 & 0.38 & 0.65 & 1.0 \\
\hline Pu-239 & $5 \times 10^{-6}$ & $2.4 \times 10^{4}$ & 1.0 & 0.65 & 1.0 \\
\hline$A m-241$ & $4 \times 10^{-6}$ & 458 & 0.79 & 0.65 & 1.0 \\
\hline$C m-244$ & $7 \times 10^{-6}$ & 18.1 & $8.8 \times 10^{-2}$ & 0.65 & 1.0 \\
\hline $\mathrm{Hg}^{\mathrm{b}}$ & $2 \times 10^{-3^{6}}$ & $\infty$ & 1.0 & 255 & 1.0 \\
\hline $\mathbf{P b}$ & $5 \times 10^{-2}$ & $\infty$ & 1.0 & 9.7 & 1.0 \\
\hline
\end{tabular}

a MPC value taken for $s n-125$.

b For $\mathrm{Hg}$, bullaup of the toxic methylated form is Ignored and $\mathrm{C}$ is assigned the value 1.0. The value for $A_{0}$ is taken to be the same as that of $C d$, which is also a Group $2 b$ trangition element.

c In mililgrams per litre. 


\section{REFERENCES}

American Conference of Governmental Industrial Hygienists, Threshold Limit Values for Chemical Substances in Workroom Air (1978).

Bateman, H., Proc. Cambridge Phil. Soc., 15, 423 (1910).

Becker, D. S., Design of a Chemical Hazara Ranking System: Final Report, prepared for the U. S. Consumer product Safety Commission under contract No. CPSC-C-77-0068 (1978).

Bell, M. J., ORIGEN - The ORNL Isotope Generation and Depletion Code, Oak Ridge National Laboratory Rept. ORNL-4628 (.1973).

Bisse1l et al., Monitoring the Environment of the Nation, MITRE Corporation, McLean, Virginia (1971) NTIS Nos. PB 205989 and PB 205990 (1971).

Brandt, C. S., "Plants as Indicators of Air Quality," in Indicators of Environmental Quality, W. A. Thomas, Ed., Plenum Press, New York (1972).

Bruns, L. B., "Hazards from Toxic Substances," from Proc. Symp. Waste Management, Tucson, Arizona, 1976.

Bruns, L. E., "Toxic Materials Avallability in Perspective," from Proc. Symp. Waste Management, Tucson, Arizona (1979).

claiborne, H. C., Effect of Actinide Removal on the Long-Term Hazard of High-Level Waste, Oak Ridge National Laboratory Rept. ORNL-TM-4724 (1975).

Code of Federal Regulations, Title 10, Chapter 1, Part 20, U. S. Government Printing Office, washington D. C., (December 1975).

Cohen, B. L., "High-Level Radioactive Waste from Light-Water Reactorg," Rev, of Modern Phys., 49 (1) (1977).

Cohen, B. L., and H. N. Jow, A Gener ic Hazard Evaluation of Low-Level Waste Burial Grounds," Nucl. Techn., 41, 38i-388 (1978).

Cohen, J. J., et al. Determination of Performance Criteria for High-Level Solidifled Nuclear Waste, Lawrence Iivermore Laboratory, Rept, NRUEG-0279 (1977).

Corbett, J. O., and H. F. MacDonald, "A Simplifled Model for Relating a Range of Reactor Accidents to their Radiological Effects," Nucl. Safety $19(4), 465-467$ (1978).

Eckart, L. E., The Relative Environmental Hazard of Fission Product Release from Defective Fuel Rods, Ph.D. Thesis, University of Cincinnati (1971). 
Eisenbud, M., Environmental Radioactivity, Academic Press, New York (1973), and ed.

Environmertal Protection Agency (FPA), Environmental Radiation Dose Commitment: An Application to the Nuclear Power Industry, USEPA Office of Radiation Programs (1974).

Environmental Protection Agency, National Interim Prlmary Drinking Water Standards, $40 \mathrm{CFR} 141$ (1975).

Finch, W. I., Geology of Epigenetic Uranium Deposits in Sandstone in the United States, United States Geological Survey, No. 538 (1967).

Ford, Bacon, and Davis, Determination of a Radioactive Waste Classification System, Lawrence Livermore Laboratory, Rept. PO 6320703, (1977).

General Electric Company, Chart of the Nuclides, (1967) 10th ed.

General Electric Company, Chart of the Nuclijes, (1977) 12th ed.

Gera, F., and D. G. Jacobs, "Hazard Potential of Radioactive Wastes," in Proc. Intern. Conf. on Radioecology Applied to Protection of Man and His Environment, EUR-4800, Rome (1971).

Gera, F., and D. G. Jacobs, Considerations in Long-Term Management of HighLevel Radioactive Wastes, Oak Ridge National Laboratory, Rept. ORNL-4762 (1972).

Hanistra, J., "Radiotoxic Hazard Measure for Burled Solldifled Radioactive Wastes," Nucl. Safety, 16, (2) (1975).

Haug, H. O., "Some Aspects and Long-Term Problems of High-Level and Actinide-Contaminated Spent Fuel Reprocessing Wasteg from the Nuclear Fuel Cycle," Oak Ridge National Laboratory, Rept. ORNL-TR-4302, translation of RFR-2022 (1977).

Hilliar, R. A., Relative Inhalation Hazards Present In Fresh Irradiated Fuel, RD/B/N-1143 (1968).

Inhaber, W., "Environmental Qual1ty: Outline for a National Index for Canada," Science, 186, 798-805 (1974).

Inhaber, W., "A Set of suggested Air Quality Indices for Canada," Atmospheric Enviroment, 9 (5), 353-364 (1975).

Inhaber, W., "An Approach to a Water Quality Index for Canada," Water Research, 9 (9), 821-833 (1975).

Inhaber, B., Environmental Indices (John Willey and Sons, New York, 1976). 
International Atomic Energy Agency (IAFA), Basic Safety Standards for Radiological protection, IAEA Safety Series No. 9, Vienna (1962).

International Commission on Raäiological Protection (ICRP), Recommendations of the International Comnission on Radiological protection, ICRP Publication No. 2, Pergamon Press (1959).

International Commission on Radiological Protection (ICRP), Recommendations of the International Commission on Radiological protection, ICRP publication No. 6, Pergamon Press (1964).

International Dommission on Radiological Protection (ICRP), Recommendations of the International Commisgion on Radiological protection, ICRP Publication 26. Annals of the ICRP, Pergamon Press (1977).

International Commission on Rariological Protection (ICRP), Report for the International Commission on Radlological Protection, "Problems Involved in Developing an Index of Harm," ICRP publication 27, Pergamon Press (1977).

Karol, M., and R. G. Post, Comprehensive Operational Waste Classification System, University of Arizona Engineering Experiment Station, Report No. 48 (1977).

Kocher, D. C., A Dynamic Model of the Global Iodine Cycle for the Estimation of Dose to the World's Population from Releases of Iodine-129 to the Environment, Oak Ridge National Laboratory, Rept. ORNL/NUREG-59 (1959) .

Laws, P. A., and M. Rosenstein, "A Somatic Dose Index for Diagnostic Radlology," 22nd Annual Mtg. Health Phys. Soc.. Atlanta (1977).

Leonard, J. H., L. E. Eckart, and J. E. Mountain, Radionuclide Production and Release in Advanced Nuclear Reactor Types, University of Cincinnat1, Final Sumary Report for contract CPE-R-69-12, (1969).

McGrath, P. E., Radioactive Waste Management Potentials and Hazards from a Risk Point of View, Rept. KFK-1992 (1974).

Morgan, K. Z., W. S. Snyder, and M. R. Ford, "Maximum Permissible Concentration of Radiolsotopes in Air and Water for Short Per lod Exposure," in Proc. 1st Intl. Canf. Peaceful Uses Atomic Energy, 13, 139-158 (1955).

Morgan, R. 2., W. S. Snyder, and M. R. Ford, "Relative Hazard of the Various Radioactive Materials," Health Physics 10, 151-169 (1964).

Munera, H. A., Modeling of Individual Risk Attitudes in Decision Making Under Uncertainty: An Application to Nuclear Power, Ph.D. Thesis, University of Callfornia, Berkeley (1978).

National Bureau of standards (NGS), "Maximum Permissible Body Burdens and Maximum Permisgible Concentrations of Radionuclides in Air and water for Occupational Exposure," NBS Handbook 69, U. S. Government Printing Office, Fashington D. C. (1959). 
Patrick, R., "Aquatic Communities as Indices of Pollution," in Indicators of Environmental Quality, W. A. Thomas, Ed. (Plenum Press, New York 1972).

Pingel, J. H. and B. D. Shlpp, "The Most Hazardous Substance," in Proc. 9th Midyear Topical Sym. Health Phys. Soc., (1976).

poston, J. W., Measures of Equivalent Hazard of Radionuclides: A Survey, School of Nuclear Engineering, Georgia Institute of Technoiogy, Rept. Y/OWI/SUB-7278/2 (1978).

Ramu, M. C. S., "An Index of Risk for Inhalation Hazard Evaluation," Health Physics, 27, 353-358 (1974).

Reiquam, H., "Establishing Priorities Among Environmental Stresses," in Indicators of Environmental Quality, W. A. Thomas, Ed. (Plenum Press, New York 1972).

Rogers, V. C., Radloactive Waste Disposal Clasgification System, Ford Bacon and Davis Utah Inc., Rept. NUREG/CR-1005 (1979).

Rohwer, P. S, et al., "Development of Radiation Safety Guides for Environmentai Releases of Radioactivity," Health Phys. Eiv. Ann. Prog. Report, Oak Ridge National Iaboratory, Rept. ORNL-I? To (October I97I).

Shipp, B. D. and J. H. Pingel, "The Concept of Environmental Burden," Proc. 9 th Midyear Topical Sym. Health Phys. Soc., 1976.

Smith, C. F., Risk Assessments for the Disposal of High-Level Radioactive Wastes, Ph.D. Dissertation, UCLA, 1975.

Smith C. F., and W. E. Rastenberg, "On Risk Assessment of High-Level

Radioactive Waste Disposal," Nucl. Eng. and Design, 39, 293-333 (1976).

Solomon, K. A., and S. C. Abrahan, The Index of Harm: A Measure for Comparing Occupational Risk Across Industries, Rand Corporation, Rept. R-2409-RC (1979).

Starr, C., and R. P. Hammond, Nuclear Waste Storage. Sclence, 177, 744-45, (1972).

Tonnesson, K. A. and Cohen, J. J., Survey of Naturally Occuring Hazardous Materials in Deep Geologic Formations: A Perspective on the Relative Hazard of Deep Bur ial of Nuclear Wastes, Lawrenve IIvermore Laboratory, Rept. UCRL-52199 (1977).

Voss, J. W., and R. G. Post, Dissolution of High-Level Nuclear Waste Sollds, University of Arizona Engineering Experiment Station, Report No. 29 (1976).

Voss, J. W., Safety Indices and Their Application to Nuclear Waste, Management Safety Assessment, Rept. PNL-2727 (1979). 
Watson, S. R., An Index of Hazard for Radioactive Kaste, Decisions and Designs Incorporated, Inter Im Technical Rept. PR 78-10-80 (I978).

Walsh, P. J. et al., CUMBX - A Cumulative Hazard Index for Assessing Limiting Exposures to Environmental Pollutants, Oak Ridge National Laboratory, Rept. ORNL-5263 (1977).

Walsh, P. J. et al., "Composite Hazard Index for Assessing Limiting Exposures to Environmental Pollutants: Formulation and Derivation," Env. Sc1. Tech., 12 (7), July 1978. 